\title{
The ToF-ACSM: a portable aerosol chemical speciation monitor with TOFMS detection
}

\author{
R. Fröhlich ${ }^{1}$, M. J. Cubison ${ }^{2}$, J. G. Slowik ${ }^{1}$, N. Bukowiecki ${ }^{1}$, A. S. H. Prévôt ${ }^{1}$, U. Baltensperger ${ }^{1}$, J. Schneider ${ }^{3}$, \\ J. R. Kimmel ${ }^{2,4}$, M. Gonin ${ }^{2}$, U. Rohner ${ }^{2}$, D. R. Worsnop ${ }^{4}$, and J. T. Jayne ${ }^{4}$ \\ ${ }^{1}$ Laboratory of Atmospheric Chemistry, Paul Scherrer Institute, Villigen, Switzerland \\ ${ }^{2}$ Tofwerk AG, Thun, Switzerland \\ ${ }^{3}$ Max Planck Institute for Chemistry, Mainz, Germany \\ ${ }^{4}$ Aerodyne Research, Inc., Billerica, Massachusetts, USA
}

Correspondence to: A. S. H. Prévôt (andre.prevot@psi.ch)

Received: 4 July 2013 - Published in Atmos. Meas. Tech. Discuss.: 25 July 2013

Revised: 21 October 2013 - Accepted: 24 October 2013 - Published: 26 November 2013

\begin{abstract}
We present a new instrument for monitoring aerosol composition, the time-of-flight aerosol chemical speciation monitor (ToF-ACSM), combining precision state-ofthe-art time-of-flight mass spectrometry with stability, reliability, and easy handling, which are necessities for long-term monitoring operations on the scale of months to years. Based on Aerodyne aerosol mass spectrometer (AMS) technology, the ToF-ACSM provides continuous online measurements of chemical composition and mass of non-refractory submicron aerosol particles. In contrast to the larger AMS, the compactsized and lower-priced ToF-ACSM does not feature particle sizing, similar to the widely-used quadrupole-ACSM (QACSM). Compared to the Q-ACSM, the ToF-ACSM features a better mass resolution of $\frac{M}{\Delta M}=600$ and better detection limits on the order of $<30 \mathrm{ng} \mathrm{m}^{-3}$ for a time resolution of $30 \mathrm{~min}$. With simple upgrades these limits can be brought down by another factor of $\sim 8$. This allows for operation at higher time resolutions and in low concentration environments. The associated software packages (single packages for integrated operation and calibration and analysis) provide a high degree of automation and remote access, minimising the need for trained personnel on site. Intercomparisons with Q-ACSM, C-ToF-AMS, nephelometer and scanning mobility particle sizer (SMPS) measurements, performed during a first long-term deployment (>10 months) on the Jungfraujoch mountain ridge (3580 m a.s.1.) in the Swiss Alps, agree quantitatively. Additionally, the mass resolution of the ToFACSM is sufficient for basic mass defect resolved peak fitting of the recorded spectra, providing a data stream not
\end{abstract}

accessible to the Q-ACSM. This allows for quantification of certain hydrocarbon and oxygenated fragments (e.g. $\mathrm{C}_{3} \mathrm{H}_{7}^{+}$ and $\mathrm{C}_{2} \mathrm{H}_{3} \mathrm{O}^{+}$, both occurring at $m / Q=43 \mathrm{Th}$ ), as well as improving inorganic/organic separation.

\section{Introduction}

Over the last decades, ongoing research efforts have solidified the knowledge base about the significant role aerosols play in Earth's ecosystem (Gu et al., 2003; Mercado et al., 2009; Mahowald, 2011) and climate (Lohmann and Feichter, 2005; Forster et al., 2007; Carslaw et al., 2010). Furthermore, evidence for severe adverse effects of aerosols on human health has been reported (Seaton et al., 1995; Laden et al., 2000; Cohen et al., 2005; Pope and Dockery, 2006), though the mechanisms of action and effect of aerosol composition remain largely unclear. To assess and address these issues a large number of air quality monitoring endeavours are needed. Essential to this are instruments capable of gathering in situ information about the chemical properties and composition of the ambient particles on a long-term basis. Such instruments can provide valuable insights into many attributes of the aerosol, e.g. source or toxicity, with higher time resolution (minutes to hours) than conventional filter sampling with subsequent post-processing. Effects on ecosystem and climate mainly occur on large temporal and spatial scales, therefore it is similarly important to be able to collect these data over long-term periods. In addition, this facilitates the 
conduct of epidemiological studies useful in assessing links between health and aerosols.

The various types of the Aerodyne aerosol mass spectrometer (hereafter denoted AMS; quadrupole-AMS: Jayne et al., 2000, compact time-of-flight (C-ToF)-AMS: Drewnick et al., 2005, high resolution time-of-flight (HR-ToF)-AMS: DeCarlo et al., 2006) have proven to be very productive and powerful tools in terms of recording aerosol mass spectra with high sensitivity. An overview of numerous AMS campaigns demonstrating the importance of organics in the total ambient $\mathrm{PM}_{1}$ aerosol budget is shown in Canagaratna et al. (2007), and Jimenez et al. (2009) used AMS data to unravel the chemical evolution of organic aerosol in the atmosphere. However, the monetary and manpower investments associated with AMS measurements and data analysis make this instrument impractical for long-term, widespread, semiautonomous monitoring initiatives.

The Aerodyne quadrupole aerosol chemical speciation monitor (Q-ACSM, Ng et al., 2011) is built upon the same sampling and detection technology as the AMS but with reduced complexity (e.g. no particle size measurement) and performance. The ACSM is specially designed for unattended monitoring applications with minimal user intervention to close the gap between AMS and filter sampling. It is able to record mass spectra of ambient non-refractory submicron aerosol with unit mass resolution (UMR) up to mass to charge ratios of $200 \mathrm{Th}$, although the region above $140 \mathrm{Th}$ is usually omitted because of its negligible contribution to aerosol mass and a decreasing transmission of the quadrupole. To date it has been used successfully by more than 40 research groups all over the world (cf. Sun et al., 2013, 2012; Budisulistiorini et al., 2013; Seto et al., 2013; Takahama et al., 2013) and has inspired some very fruitful international cooperations like the ACSM subgroup of the European ACTRIS (Aerosols, Clouds, and Trace gases Research Infrastructure Network) project (www.psi. $\mathrm{ch} / \mathrm{acsm}$-stations). Besides the individual scientific output of every instrument, the unique databases produced with the ACSM by such monitoring networks comprise a combination of chemical information, high time resolution, longterm measurements, and more, like the ability to measure semivolatile nitrate and organics without filter artefacts or offline analysis. This provides invaluable opportunities for the modelling community.

In this manuscript, we present a new instrument based on AMS and ACSM technology, the time-of-flight ACSM (ToF-ACSM). This instrument retains the advantages of the Q-ACSM such as compact design, semi-autonomous operation, and relatively low cost, while greatly improving mass resolution and detection limits. It is equipped with a Tofwerk ETOF (economy time-of-flight) ion mass spectrometer. Upgrades are possible since the hardware is compatible with any Tofwerk TOF platforms. Here we discuss the operation, testing, and initial deployment of a ToF-ACSM for a period of $>10$ months at the high altitude research station, the
Jungfraujoch (JFJ, $3580 \mathrm{~m}$ a.s.l.), in the Swiss Alps. This deployment demonstrated the instrument stability, sensitivity, and enabled quantitative comparison with other aerosol mass spectrometers and particle instruments.

\section{Apparatus}

The components of the ToF-ACSM are mounted in a rectangular rack with edge lengths of $65 \mathrm{~cm} \times 51 \mathrm{~cm} \times 60 \mathrm{~cm}$, it weights $75 \mathrm{~kg}$ and consumes approximately $330 \mathrm{~W}$ when the inlet valve is open (to compare Q-ACSM: $48.3 \mathrm{~cm} \times 53.3 \mathrm{~cm} \times 83.8 \mathrm{~cm}, \quad 63.5 \mathrm{~kg}, \quad 300 \mathrm{~W}$; HR-ToFAMS: $104 \mathrm{~cm} \times 61 \mathrm{~cm} \times 135 \mathrm{~cm}, 170 \mathrm{~kg}, 600 \mathrm{~W}$ ). This compact size facilitates transport and enables a simpler integration into existing monitoring stations or places where space is limited, e.g. aeroplanes.

Figure 1 shows a scheme of the ToF-ACSM with the main components. A primary difference between the ToF-ACSM and the Q-ACSM and AMS is the different vacuum system design. The vacuum chamber, which has a total length of $43 \mathrm{~cm}$ (Q-ACSM: same; AMS: $59 \mathrm{~cm}$ ) is divided into four differentially pumped sections. A Pfeiffer SF270 4-stage turbomolecular pump (www.pfeiffer-vacuum.com) is mounted directly to the vacuum chamber, and backed by the same Vacuubrand MD1 diaphragm pump (www.vacuubrand.com) utilised in all AMS systems. The analyser is evacuated through a direct opening to the vacuum chamber and thus does not require an additional pump. The pressure is reduced over the stages from $\sim 5 \times 10^{-2}$ mbar at the exit of the aerodynamic lens to $\sim 10^{-7}$ mbar in the ionisation chamber containing vaporiser and ioniser (for a closer description of inlet and vaporiser/ioniser see Sect. 2.1). The electronics required for operation of the system, the acquisition PC and the data acquisition (DAQ) card are all mounted within the instrument rack.

\subsection{Operational principle}

Aerosol enters the instrument over the inlet system on the frontal face of the vacuum chamber. This inlet system consists of an automatic 3-way valve switch system, the aerodynamic lens and a critical orifice. Aerodynamic lens as well as the vaporiser/ioniser system are identical to those used in both the Q-ACSM (Ng et al., 2011) and the research grade AMS (Jayne et al., 2000) instruments, except that vaporiser and ioniser are divided into two parts to allow the filament flange to be removed easily.

With the valve switching system a filter is interposed periodically into the flow of ambient air to the instrument in order to measure the background signal. The particle signal is then obtained by taking the difference between the total signal measured without a filter ("sample mode") and the background signal measured with filter ("filter mode"). This follows the principle applied in the Q-ACSM and utilises the 


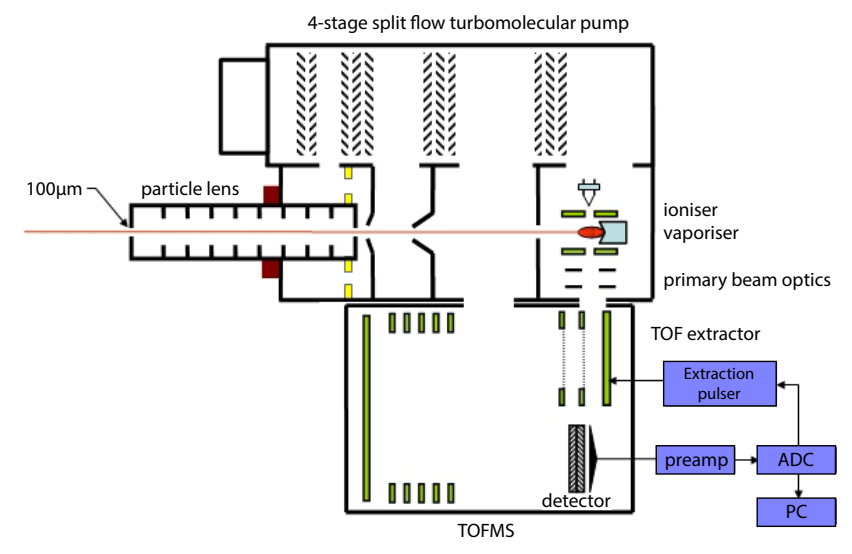

Fig. 1. ToF-ACSM schematic. Ioniser/vaporiser as well as detector are easily accessible through two vacuum flanges at the backside of the chambers. This enables an easy interchange of the ioniser filaments or between the various suitable detector types.

same switching hardware. The sample flow into the instrument is controlled by a critical orifice. The orifice diameter for operation under normal pressure conditions is $100 \mu \mathrm{m}$, admitting a flow of $1.4 \mathrm{~cm}^{3} \mathrm{~s}^{-1}$.

The aerodynamic lens (Liu et al., 1995a, b; Liu et al., 2007; Zhang et al., 2004), which consists of a series of apertures with decreasing diameter, focuses the submicron particles in the aerosol in a narrow beam into the vacuum chamber while the gases diverge. The lighter air molecules are preferentially stripped from the aerosol beam as it passes through skimmers separating the 4 differentially-pumped chambers. Position and design of the skimmers are particularly important for ACSM instruments because of the shorter vacuum chamber compared to the AMS. High signals caused by atmospheric gases reduce the lifetime of the detector significantly and contribute to interferences in the aerosol mass spectrum.

At ambient pressure (1013 mbar) the lens system has a close to $100 \%$ transmission at vacuum aerodynamic diameters between $d_{\mathrm{va}}=150 \mathrm{~nm}$ and $d_{\mathrm{va}}=450 \mathrm{~nm}$ and an upper cut-off ( $<15 \%$ transmission) around $d_{\mathrm{va}}=1 \mu \mathrm{m}$ (Liu et al., 2007). The transmission for smaller particles $(<100 \mathrm{~nm})$ is somewhat reduced compared to the Q-ACSM, which is a result of the different vacuum systems and pumping speeds at the lens exit chamber. A recently developed aerodynamic lens extends the particle transmission to several micrometre (Williams et al., 2013) and is compatible with the ToFACSM.

At the end of the chamber, the particle beam impacts on a resistively heated porous tungsten surface $\left(T \approx 600^{\circ} \mathrm{C}\right)$. There the non-refractory constituents in the particles flash vaporise and are subsequently ionised by electron impact. The electrons used for the ionisation $\left(E_{\text {kin }}=70 \mathrm{eV}\right)$ are emitted by a tungsten filament arranged perpendicular to the particle beam in the vaporisation region. The ioniser flange, unlike on existing AMS systems, may be directly removed from the vacuum chamber, allowing a quick and easy replacement of the filaments. The same principle applies to the detector flange.

Numerous experiments with AMS and Q-ACSM have shown that a fraction of the non-refractory particles does not flash vaporise at the vaporiser but bounces off the oven and subsequently is not detected (Canagaratna et al., 2007; Matthew et al., 2008). A collection efficiency (CE) factor was introduced to correct for this effect. In the majority of cases the $\mathrm{CE}$ is approximately $\mathrm{CE}=0.5$. The $\mathrm{CE}$ caused by particle bounce increases with increasing particulate water content, acidity, and nitrate fraction (Middlebrook et al., 2012). Because it is not possible to quantitatively determine the water content, a drying system (e.g. Nafion membrane driers from Perma Pure MD, www.permapure.com) is typically installed on the sampling inlet. The campaign and instrument specific $\mathrm{CE}$ can be assessed for example by correlation to co-located measurements (e.g. SMPS + aethalometer) or by theoretical considerations using the measured chemical composition, as described by Middlebrook et al. (2012).

\subsection{Time-of-flight mass analyser}

The Tofwerk ETOF mass analyser is based on the CTOF analyser used by the first-generation ToF-AMS systems (Drewnick et al., 2005), and shares the same housing and interface connections. However, the fine grids used to develop the electric fields which guide the ions are replaced with metallic plates, providing a more robust, economical solution at the expense of resolving power and sensitivity. Fewer voltages (drift tube: $\sim 3000 \mathrm{~V}$, reflector backplane and grid: $200-800 \mathrm{~V}$, pulser: $\sim 800 \mathrm{~V}$, detector: $\sim 3500 \mathrm{~V}$ ) are required to operate the analyser, reducing the complexity of the power supply and potential for failure during long-term operation. The ions are detected using an SGE dynode detector (www.sge.com), which are much more robust than the micro-channel plates (MCP) used in standard AMS systems and can handle exposure to atmospheric pressure and humidity. The detector lifetime of the instrument deployed at the Jungfraujoch for this study was $1 \mathrm{yr}$. Together, the use of the ETOF + SGE system gives an 8-fold (4-fold SGE $\times$ 2 -fold ETOF) reduction in sensitivity as compared to the CTOF + MCP (for detection limits see Sect. 3.2), and a mass resolving power $\left(\frac{M}{\Delta M}\right)$ of $\sim 600$ instead of $\sim 1000$. It is noted that a specially-designed flange, which bolts directly onto the end of the vacuum chamber, is used to hold the detector mount, providing unconstrained access and allowing for fast replacement of an old detector or quick swap-out to a higher-sensitivity MCP detector for specific time periods of interest. This is in contrast to the Q-ACSM system where the quadrupole head has to be disassembled to replace the detector or the AMS where the entire mass analyser must be removed. 


\subsection{Data acquisition and analysis}

The signals are digitised using a USB-based acquisition card connected to a compact PC. The 14-bit analogue-to-digital converter digitises the analogue signal into $2^{14}$ discrete levels at $0.8 \mathrm{GS} \mathrm{s}^{-1}$ with a maximum mass spectrum acquisition rate of $200 \mathrm{~Hz}$ and maximum averaging depth of $65535 \mathrm{ex}-$ tractions/spectrum. The 64-fold increase in the resolution of the digitisation with respect to the Acqiris AP240 card used in the AMS allows for a much more accurate setting of both the electronic baseline and noise suppression threshold. The increased dynamic range also affords higher fidelity recording of single ion signals, and thus improved linearity in instrument response.

Data are recorded using the TofDaq data recorder from Tofwerk AG, which are fed into presentation and analysis using the Tofwerk "IgorDAQ" package running under the Igor environment (WaveMetrics Inc., OR, USA).

The background and total air measurements are alternated through automated, synchronised switching of an inlet valve such that the resulting time series data resemble that of "fastmode" MS of the AMS (Kimmel et al., 2011). In this mode of operation, the background is assumed stable over the timescale of a single data point $(10 \mathrm{~min})$, and recorded for only $1 \mathrm{~min}$ before switching to total air sampling for the remaining $9 \mathrm{~min}$. To ignore transients in the inlet, the first $20 \mathrm{~s}$ of data after a valve switch must be discarded.

The software then interpolates and optionally smoothes a running background trend between the filter data points, which is then subtracted from the individual total measurements. The ionisation efficiency (IE), $m / Q$ and flow calibrations, baseline subtraction, sensitivity correction and fragmentation patterns (Jayne et al., 2000; Jimenez et al., 2003; Allan et al., 2004; Drewnick et al., 2005) are applied, yielding the integrated species time trends at a maximum $20 \mathrm{~s}$ temporal resolution. The saved data products thus consist of Tofwerk-format HDF files, containing the full mass spectra and associated diagnostics, and of $10 \mathrm{~min}$ and $1 \mathrm{~h}$ timescale tab-delimited text files of mass loading time trends and important diagnostics, and organic species spectrum matrices suitable for analysis by tools such as the multilinear engine ME-2 (Paatero, 1999; Canonaco et al., 2013) and positive matrix factorisation (PMF; Paatero, 1997; Paatero and Tapper, 1994). In addition, IgorDAQ is designed to operate with the application programming interface from Google Inc. (www.google.com), allowing for the automated upload of data to a dedicated, password-protected location and subsequent parsing and display of data products in Web browsers and on mobile devices using publicly-available JavaScript widgets. The DAQ may also be configured to read parameters from the server before the start of each measurement cycle, for example if a change in the filament emission current were desired. This alleviates the need for remote-desktop applications for which the Internet connection may, particularly at remote sites, not be sufficient. Finally, the instrument start-up operation is automated, including pumping down of the vacuum chambers, making it suitable for operation in the absence of trained personnel.

For further, more detailed analysis of the data, the HDF files may be analysed using the Igor-based "Tofware" package, which offers the usual analysis features employed by the atmospheric science community such as mass calibration, peak integration and high-resolution peak fitting. A dedicated plug-in to the Tofware base package is employed to deal with the application of ACSM-specific corrections, filter subtraction and other instrument-specific requirements.

\section{Quantification of aerosol mass}

The ToF-ACSM provides mass spectra of non-refractory submicron particulate material that vaporises at $\sim 600^{\circ} \mathrm{C}$ and $\sim 10^{-7}$ mbar. Further speciation (e.g. into nitrate, sulphate, chloride, ammonium, and organic compounds) is attained through analysis of fragmentation patterns (Allan et al., 2004).

\subsection{Calibrations}

For the mass spectra to become quantitative, a number of calibrations are necessary to relate raw detector signals to quantitative mass spectra and to account for changes inside (detector signal decay) or outside (pressure) the instrument.

\subsubsection{Inlet flow}

The dependency of the pressure measured after the critical orifice on the flow has to be calibrated to detect and eventually correct for changes in the inlet flow during operation. This can be done by connecting a sensitive needle valve to the inlet and recording the pressure and flow while opening it stepwise.

\subsubsection{Baseline and detector}

In the ToF-ACSM the retrieval of the conversion factor from a signal amplitude at the detector measured in $\mathrm{mV} \times \mathrm{ns}$ to ions $\mathrm{s}^{-1}$, the so-called single ion calibration, is fully automatised. The same applies to the determination of the spectrum's appropriate baseline and the detector gain. In regular intervals the system checks and, if necessary, readjusts the baseline and gain settings autonomously.

Analogously to all AMS systems, variations of the nitrogen signal at $m / Q=28 \mathrm{Th}$ which is assumed to be constant due to its abundance in the atmosphere can be used to correct for intrinsic changes in the instrument like a decay of the ion detector signal in the ToF module occurring between the automatic gain adjustments. 


\subsection{3 $m / Q$}

Easily identifiable ions from the chamber background are used to determine $m / Q$ as a function of ion time-of-flight. As highlighted in Fig. 2, for ambient sampling, ions selected at the low $m / Q$ end of the spectrum typically include nitrogen $\left(\mathrm{N}_{2}^{+}: 28.0067 \mathrm{Th}\right)$, oxygen $\left(\mathrm{O}_{2}^{+}: 31.9904 \mathrm{Th}\right)$, argon $\left(\mathrm{Ar}^{+}\right.$: $39.9629 \mathrm{Th})$ and carbon dioxide $\left(\mathrm{CO}_{2}^{+}: 43.9904 \mathrm{Th}\right)$. Since the calibration function is non-linear, one also needs a calibration point in the heavy end of the spectrum. As long as one uses tungsten filaments in the ioniser, ions of the four stable isotopes of tungsten ${ }^{182} \mathrm{~W}^{+},{ }^{183} \mathrm{~W}^{+},{ }^{184} \mathrm{~W}^{+}$and ${ }^{186} \mathrm{~W}^{+}$will always be visible and can be used for the $m / Q$ calibration. In the $m / Q$ calibration depicted in Fig. 2, the isotope with the nucleon number $A=184\left({ }^{184} \mathrm{~W}^{+}: 183.9509 \mathrm{Th}\right)$ was used. The $m / Q$ calibration is dynamically adjusted every $10 \mathrm{~min}$ by the software to account for potential drifts in instrument performance during deployment, e.g. in response to changes in room temperature.

\subsubsection{Signal-to-mass}

To quantify the mass concentrations measured by the ToFACSM, the signal to mass relation of the device has to be determined. A mass-based calibration method using the massbased ionisation efficiency mIE (Onasch et al., 2011) given in ions measured per picogram of aerosol particles entering the instrument is applied. Equation (1) yields the mass concentration $\gamma_{i}$ of a species $i$ derived from the measured signals $I_{i, j}$ of its mass fragments $j$.

$\gamma_{i}=\frac{1}{\left(\mathrm{mIE}_{i} \cdot q \mathrm{~V}\right)} \cdot \sum_{j} I_{i, j}$

with $\gamma_{i}$ in units of $\mu \mathrm{g} \mathrm{m}^{-3}, \mathrm{mIE}_{i}$ in ions $\mathrm{pg}^{-1}, I_{i, j}$ in ions $\mathrm{s}^{-1}$ and the volumetric sample flow $q_{\mathrm{V}}$ in $\mathrm{cm}^{3} \mathrm{~s}^{-1}$. As the $\mathrm{mIE}_{i}$ is different for every ambient species, it is convenient to express the different $\mathrm{mIE}_{i}$ in terms of $\mathrm{mIE}_{\mathrm{NO}_{3}}$ (i.e. the mIE of the sum of the main nitrate fragments: $\mathrm{NO}^{+}$at $m / Q=30 \mathrm{Th}$ and $\mathrm{NO}_{2}^{+} m / Q=46 \mathrm{Th}$ ) determined in the calibration (see Eq. 3 below and Jimenez et al., 2003). To this end, a relative ionisation efficiency RIE is defined:

$\mathrm{RIE}_{i}=\frac{\mathrm{mIE}_{i}}{\mathrm{mIE}_{\mathrm{NO}_{3}}}$.

The $\mathrm{RIE}_{i}$ of a species $i$ with respect to the mass-based ionisation efficiency of $\mathrm{NO}_{3}$ is unitless. Commonly used RIE values are 1.4 for organics and 1.3 for chloride. The RIE values of $\mathrm{NH}_{4}$ and $\mathrm{SO}_{4}$ should be calibrated at the beginning of each deployment and then be reviewed on a regular basis. Typically they lie between $2.5-5$ and $0.6-1.2$, respectively. During the long-term measurement at the Jungfraujoch, the ToF-ACSM RIEs were $\mathrm{RIE}_{\mathrm{NH}_{4}}=3.23 \pm 0.42$ and $\mathrm{RIE}_{\mathrm{SO}_{4}}=0.65 \pm 0.05$.

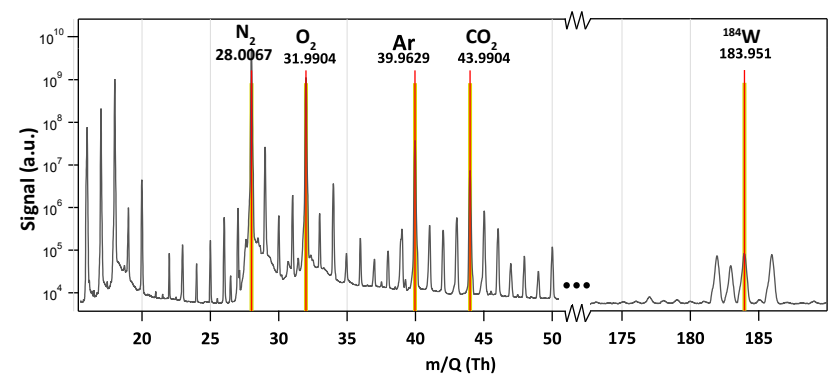

Fig. 2. Raw mass spectrum of the ToF-ACSM (logarithmic scale). The $x$ axis is interrupted between $m / Q=50 \mathrm{Th}$ and $175 \mathrm{Th}$ to show all peaks used in the mass-to-charge calibration. The calibration peaks are as follows: nitrogen $\left(\mathrm{N}_{2}: 28.0067 \mathrm{Th}\right)$, oxygen $\left(\mathrm{O}_{2}: 31.9904 \mathrm{Th}\right)$, argon $(\mathrm{Ar}: 39.9629 \mathrm{Th})$, carbon dioxide $\left(\mathrm{CO}_{2}\right.$ : 43.9904 Th), and tungsten ( $\left.{ }^{184} \mathrm{~W}: 183.9509 \mathrm{Th}\right)$.

For the mIE calibrations, ammonium nitrate $\left(\mathrm{NH}_{4} \mathrm{NO}_{3}\right)$ particles of known size and concentration are needed, similar to the calibrations of the Q-ACSM (Ng et al., 2011). Hence, the same calibration equipment is required. $\mathrm{NH}_{4} \mathrm{NO}_{3}$ is mainly used because it is easily accessible and atomised, vaporises with $100 \%$ efficiency to ions from the ammonium and nitrate species. $\mathrm{NH}_{4} \mathrm{NO}_{3}$ is also well focused by the aerodynamic lens and does not experience particle bounce at the vaporiser. Particles of $\mathrm{NH}_{4} \mathrm{NO}_{3}$ can be produced from an aqueous solution by a nebuliser, size selected with a DMA after being dried by, e.g. a silica gel drier and then fed simultaneously to the ToF-ACSM and a CPC for counting.

With the equipment described above, a fixed amount (between 300 and $1500 \mathrm{~cm}^{-3}$ ) of $\mathrm{NH}_{4} \mathrm{NO}_{3}$ calibration aerosol particles with a uniform mobility diameter in the range between $d_{\mathrm{m}}=300-350 \mathrm{~nm}$ are selected with the DMA and sampled by the instrument. This diameter and concentration range is recommended because there the lens still has unit transmission and the error caused by doubly charged particles is minimised. Great care should be taken in the set-up of DMA and CPC. Uncertainties in number concentration or particle size will obviously reduce the accuracy of the mIE calibration. The software then automatically calculates the $\mathrm{mIE}_{\mathrm{NO}_{3}}$ only from the signal of the $\mathrm{NO}^{+}$and $\mathrm{NO}_{2}^{+}$fragments of the nitrate using Eq. (3):

$\mathrm{mIE}_{\mathrm{NO}_{3}}=\frac{I_{\mathrm{NO}_{3}, m / Q=30}+I_{\mathrm{NO}_{3}, m / Q=46}}{n \cdot \rho V \cdot f \cdot q \mathrm{~V}}$.

Here $I_{i, j}$ are the ion signals in ions $\mathrm{s}^{-1}, n$ is the number of particles measured with the $\mathrm{CPC}$ in $\mathrm{cm}^{-3}, \rho$ the density of $\mathrm{NH}_{4} \mathrm{NO}_{3}$ in $\mathrm{g} \mathrm{cm}^{-3}, V$ the volume of one $\mathrm{NH}_{4} \mathrm{NO}_{3}$ particle in $\mathrm{cm}^{3}, f$ the fraction of $\mathrm{NH}_{4} \mathrm{NO}_{3}$ that is nitrate and $q_{\mathrm{V}}$ the sampling flow in $\mathrm{cm}^{3} \mathrm{~s}^{-1}$. At the same time the $\mathrm{RIE}_{\mathrm{NH}_{4}}$ is determined from the signal of the ammonium fragments at $m / Q=15,16$ and $17 \mathrm{Th}$ via the mass fraction of $\mathrm{NH}_{4}$ in $\mathrm{NH}_{4} \mathrm{NO}_{3}$. 
Figure 3 shows the summed ToF-ACSM signal of nitrate (blue, left axis) and of ammonium (orange, right axis) at several mass concentrations of the respective species sampled by the ToF-ACSM. For both ions, a linear response of the signal to mass concentration is observed over a wide range of concentrations. Note that the higher ammonium signal (despite less mass) results from the high $\mathrm{RIE}_{\mathrm{NH}_{4}}$ (2.99).

The final $\mathrm{RIE}_{\mathrm{NO}_{3}}$, which later is applied to the ambient data, is slightly higher than one $\left(\mathrm{RIE}_{\mathrm{NO}_{3}}\right.$,ambient $\left.=1.1\right)$ because the two fragments of nitrate used in the calibration only account for about $90 \%$ of the total nitrate signal. The part of nitrate that fragments into separate nitrogen or oxygen atoms is not monitored in the calibration because of the low signal to background ratio at the corresponding $m / Q$ ratios.

Once $\mathrm{RIE}_{\mathrm{NH}_{4}}$ has been measured, the RIE of sulphate $\left(\mathrm{RIE}_{\mathrm{SO}_{4}}\right)$ can easily be determined by sampling $\left(\mathrm{NH}_{4}\right)_{2} \mathrm{SO}_{4}$ particles and adjusting $\mathrm{RIE}_{\mathrm{SO}_{4}}$ to yield ion balance between ammonium and sulphate.

It is recommended to repeat the signal-to-mass calibration at least every 8 weeks during normal operation and with increased frequency following a venting of the vacuum chamber.

\subsection{Detection limits}

The chemical species detectable with the ToF-ACSM (organics, ammonium, nitrate, sulphate and chloride) are retrieved by a recombination of ionic signals of the single fragments that the species break down to during ionisation and vaporisation (Allan et al., 2004). In the following, detection limits are defined as three times the standard deviation $(3-\sigma)$ from zero at a $1 \mathrm{~min}$ time resolution. They can be scaled to different averaging times using the formula

$\mathrm{DL}_{t}=\mathrm{DL}_{1 \min } \cdot \sqrt{\frac{60 \mathrm{~s}}{t}}$

with the detection limit of 1 min $\mathrm{DL}_{1 \mathrm{~min}}$ and $\mathrm{DL}_{t}$ being the detection limit for a given averaging time $t$. Detection limits are largely governed by the extent to which background signal originating from ions of ambient gases (mainly $\mathrm{O}_{2}, \mathrm{~N}_{2}$, $\mathrm{Ar}, \mathrm{H}_{2} \mathrm{O}$, and $\mathrm{CO}_{2}$ ) interferes with measurement of a selected species. Species with significant signal at $m / Q$ affected by such background signal have higher detection limits.

To measure the detection limits, an additional filter was placed on the ToF-ACSM inlet before the standard filtered/unfiltered switching valve, yielding a constant stream of particle-free air. Figure $4 \mathrm{a}$ shows the time series of the difference signal (difference between the signal at the two positions of the switching valve) of this particle-free air. This signal is centred at zero by definition, with the observed fluctuations determining species-dependent detection limits. Each data point in Fig. 4 was obtained from $20 \mathrm{~s}$ of averaging, with the background signal recorded every $360 \mathrm{~s}$ (visible as gaps in the data stream). The higher interferences of water vapour and other atmospheric gases with the

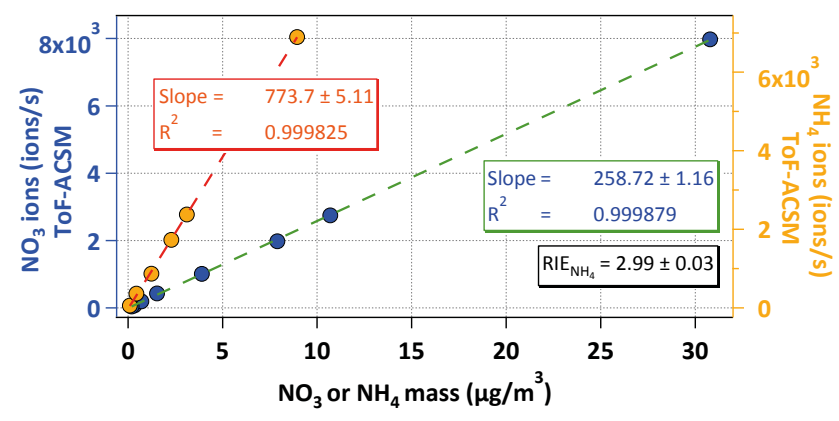

Fig. 3. $\mathrm{NO}_{3}$ (blue) and $\mathrm{NH}_{4}$ (orange) ionic signals from the mIE calibration plotted against the mass of the respective species, calculated from the output of the CPC. The dashed lines represent linear fits to the NH4 (red) and NO3 signals (green). The corresponding slopes and coefficients of determination are given in the boxes (red: $\mathrm{NH}_{4}$; green: $\mathrm{NO}_{3}$ ). The $\mathrm{RIE}_{\mathrm{NH}_{4}}$ was calculated from the ratio of the determined slopes.

ammonium and organic signals are evident, yielding variability of $\pm 0.2 \mu \mathrm{g} \mathrm{m}^{-3}$, while nitrate, sulphate, and chloride vary only $\pm 0.025 \mu \mathrm{g} \mathrm{m}^{-3}$.

The table in Fig. 4b compares published 3- $\sigma$ detection limits of each species in $\mathrm{ng} \mathrm{m}^{-3}$ for the Q-ACSM $(\mathrm{Ng}$ et al., 2011; Sun et al., 2012) and ToF-AMS (DeCarlo et al., 2006) instruments, scaled by Eq. (4), with those for the ToF-ACSM equipped with the SGE detector. At 1 min time resolution they are $182 \mathrm{ng} \mathrm{m}^{-3}$ for ammonium, $198 \mathrm{ng} \mathrm{m}^{-3}$ for organics, $18 \mathrm{ng} \mathrm{m}^{-3}$ for sulphate, $21 \mathrm{ng} \mathrm{m}^{-3}$ for nitrate, and $11 \mathrm{ng} \mathrm{m}^{-3}$ for chloride. In addition we report the detection limits for a Q-ACSM measured simultaneously at the Jungfraujoch (for more information we refer to Sect. 4.1) to those reported for the ToF-ACSM. In this context it is important to note that the detection limits are not absolute but will vary as a function of the background mass spectral signal (Drewnick et al., 2009). Aim of future work is to further reduce the impact of the airbeam on the recorded signals. First tests have demonstrated that an order of magnitude reduction in the air-to-aerosol signal ratio compared to the current configuration presented in this manuscript is feasible while keeping the total aerosol throughput high enough. This corresponds to improvements of $\sim 3$ times in organic species sensitivity.

An upgrade from the currently used SGE detector to the less-robust and shorter-lived MCPs will decrease the shown detection limits of all species by another factor of about 4 .

With the two modifications described above, the ToFACSM would advance into the domain of the C-ToF-AMS whose detection limits are currently still lower by factors between 10 and 20, except for the chloride whose detection limit with $11 \mathrm{ng} \mathrm{m}^{-3}$ already lies at a similarly low level like in the C-ToF-AMS $\left(4 \mathrm{ng} \mathrm{m}^{-3}\right)$ and in the V-mode HR-ToFAMS $\left(12 \mathrm{ng} \mathrm{m}^{-3}\right)$. The V-mode HR-ToF-AMS has a better mass resolution but also slightly higher detection limits than 


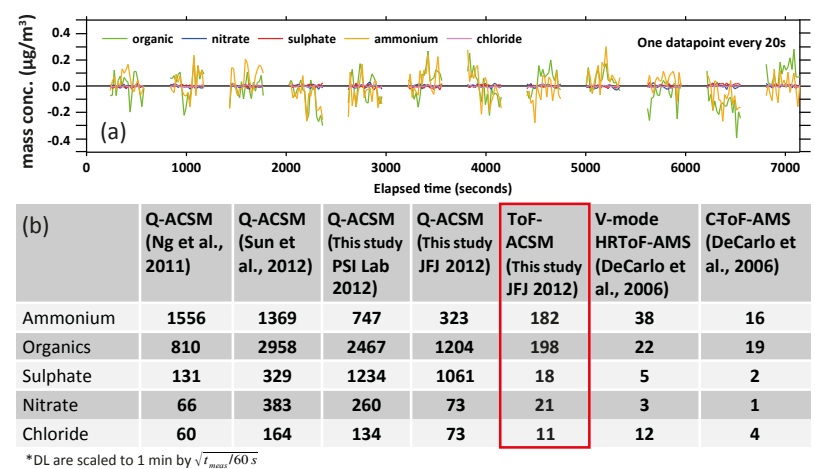

Fig. 4. (a) Signals of filtered air (in $\mu \mathrm{g} \mathrm{m}^{-3}$ ) recorded with an averaging time of $20 \mathrm{~s}$. During the gaps in the time series the background signal was monitored. Green: organics, red: sulphate, blue: nitrate, orange: ammonium, pink: chloride. (b) Overview over the $1 \mathrm{~min}$ detection limits in $\mathrm{ng} \mathrm{m}^{-3}(3-\sigma)$ of the ToF-ACSM equipped with the SGE detector (red box), Q-ACSM, HR-ToF-AMS in V-mode and C-ToF-AMS.

the C-ToF-AMS. Compared to the ToF-ACSM, the species dependent limits of the V-mode HR-ToF-AMS are lower by factors between 4 and 9 .

The ToF-ACSM improves on the detection limits reported for the Q-ACSM by Ng et al. (2011) by factors of $8.5\left(\mathrm{NH}_{4}\right)$, 4.1 (organics), $7.3\left(\mathrm{SO}_{4}\right), 3.1\left(\mathrm{NO}_{3}\right)$, and $5.5(\mathrm{Cl})$. Compared to the Q-ACSM detection limits reported by Sun et al. (2012), the ToF-ACSM shows improvement by a speciesdependent factor of 7.5 to 18.3 . The difference between $\mathrm{Ng}$ et al. (2011) and Sun et al. (2012) is probably due to the different environments the instruments were situated in, i.e. higher pollution levels also cause higher background signals. The same difference can be observed in the detection limits measured with Q-ACSM used for the intercomparison presented in Sect. 4.2.1. The average ambient mass concentrations and relative humidity are much higher at PSI than at the high alpine station on the Jungfraujoch. The values observed in the PSI laboratory are comparable to the values recorded in Beijing by Sun et al. (2012), while the results from the Jungfraujoch are comparable to $\mathrm{Ng}$ et al. (2011). This is true for the organics, the nitrate and the chloride. The ammonium and sulphate detection limits, however, are very different in our instrument. A possible explanation is that the QACSM sensitivity to these species depends more strongly on mass spectrometer tuning and therefore is more instrumentspecific. The side by side comparison of the Q-ACSM and the ToF-ACSM on the Jungfraujoch show an improvement of the detection limits with the latter by factors of 1.8 (ammonium), 6.1 (organics), 58.9 (sulphate), 3.5 (nitrate), and 6.6 (chloride). The enhancement is lowest for ammonium, which is most affected by air and water interference, and highest for sulphate, having a surprisingly high limit of detection in our Q-ACSM system.
The lower detection limits of the ToF-ACSM allow for the operation at higher time resolutions (multiple data points per minute) while achieving detection limits needed for ambient sampling. This makes it well suited for situations where fast changes in concentration like short-term plumes are expected. The ToF-ACSM also provides significant advantages in measurement locations with slower temporal variability but lower concentrations due to its lower detection limits. For example, the ToF-ACSM detection limit for organics at a $15 \mathrm{~min}$ time resolution is $51.1 \mathrm{ng} \mathrm{m}^{-3}$. For such a low concentration to fall above the Q-ACSM detection limit, approximately $9 \mathrm{~h}$ of integration would be required (based on the Jungfraujoch detection limits scaled by Eq. 4).

\section{First data set and intercomparisons}

The initial deployment of the ToF-ACSM took place at the Sphinx Observatory of the High Altitude Research Station Jungfraujoch. The (ongoing) measurements proved the instrument's stability and suitability for unattended long-term monitoring operation. To date it has produced more than ten months of quantitative mass spectra of the alpine ambient aerosol. Here we discuss ToF-ACSM performance during this initial deployment and intercomparisons with co-located instrumentation.

\subsection{General information}

The Sphinx Observatory of the High Altitude Research Station Jungfraujoch is located in the high Alps of the Bernese Oberland (Switzerland) on top of an exposed rock formation ( $3580 \mathrm{~m}$ a.s.l.) in the ridge between the mountains Jungfrau and Mönch (coordinates: $07^{\circ} 59^{\prime} 02^{\prime \prime} \mathrm{E}, 46^{\circ} 32^{\prime} 53^{\prime \prime} \mathrm{N}$ ). It is accessible by cog railroad year-round and connected to the Internet, which facilitates the unattended operation of instruments by enabling remote access.

While the temperature inside the laboratory is kept more or less constant above $20^{\circ} \mathrm{C}$ and the inlet is constantly heated to $25^{\circ} \mathrm{C}$, the monthly average outside temperature on the Jungfraujoch stays below the freezing point of water all year (between $-1.2^{\circ} \mathrm{C}$ in July and August and $-14.2^{\circ} \mathrm{C}$ in February). The temperature difference between inside and outside and the generally low relative humidity at that altitude guarantee dry aerosol without the need for additional drying equipment. Because of the low atmospheric pressure (on average around $650 \mathrm{mbar}$ ), a $130 \mu \mathrm{m}$ critical orifice was used in place of the standard $100 \mu \mathrm{m}$ orifice to retain the normal sample mass flow rate. To minimise losses in the $5 \mathrm{~mm}$ copper tubing of the $\sim 2 \mathrm{~m}$ inlet line, an additional flow of about $50 \mathrm{~cm}^{3} \mathrm{~s}^{-1}$ (sample flow $\sim 2.4 \mathrm{~cm}^{3} \mathrm{~s}^{-1}$ ) is used.

The aerosol concentrations at the Jungfraujoch are low (average $\mathrm{PM}_{10}$ concentration in 2012: $\sim 3 \mu \mathrm{g} \mathrm{m}^{-3}$; BAFU, 2012), approximately $25 \%$ of which is mineral dust (Collaud Coen et al., 2004) originating to a considerable part 
from occasional Saharan dust events. These refractory particles are not detectable with the ACSM. These low concentrations occur because the station lies within the clean continental free troposphere most of the year, especially in winter, while in summer aerosol generated at lower altitudes reaches the Jungfraujoch due to vertical exchange processes (Lugauer et al., 1998; Henne et al., 2004). The Jungfraujoch site is a famous tourist destination and the Sphinx Observatory can also be visited by tourists, leading to occasional local emission plumes from, e.g. helicopters, snow crawlers, restaurants or cigarette smoke.

Local time on the Jungfraujoch is Central European Time (UTC + 01:00), using daylight saving time in summer $(\mathrm{UTC}+02: 00)$. All data reported in this manuscript is given in UTC.

\subsection{Intercomparisons}

The High Altitude Research Station Jungfraujoch is integrated into several monitoring networks, including the Swiss national air pollution monitoring network NABEL (Nationales Beobachtungsnetz für Luftfremdstoffe), the GAW (Global Atmosphere Watch) programme of the WMO (World Meteorological Organization) and the European ACTRIS (Aerosols, Clouds, and Trace gases Research InfraStructure Network) network. As such, a large number of colocated long-term measurements of both gas- and aerosolspecies are conducted. For example, continuous long-term measurements of the aerosol scattering coefficient (with a nephelometer) and the particle number size distribution (with a scanning mobility particle sizer, SMPS) are performed within the framework of the GAW program, and a Q-ACSM was operated at the JFJ as part of the ACTRIS monitoring project during the second half of 2012. In addition, during the intensive INUIT-JFJ/CLACE (Ice Nuclei Research Unit/CLoud and Aerosol Characterization Experiment) campaign of February 2013, additional instruments were deployed at the Jungfraujoch site, including a C-ToFAMS. Data from these were used to intercompare with those recorded by the ToF-ACSM.

\subsubsection{Q-ACSM}

The Q-ACSM was operated for five months alongside the ToF-ACSM at the Jungfraujoch site, utilising a shared inlet line.

In Fig. 5a, the mass concentration of the organic fraction measured by the two instruments over the course of the 10 August 2012 is shown. This day provides the opportunity to study the output mass spectra at three different interesting situations circled in the figure. These situations are (1) concentrations well above the detection limit of the Q-ACSM between 14:00 and 16:00 (yellow, organic mass concentration $\gamma_{\text {org }} \approx 1.90 \mu \mathrm{g} \mathrm{m}^{-3}$ ), (2) concentrations close to the Q-ACSM detection limit between 04:00 and 06:00
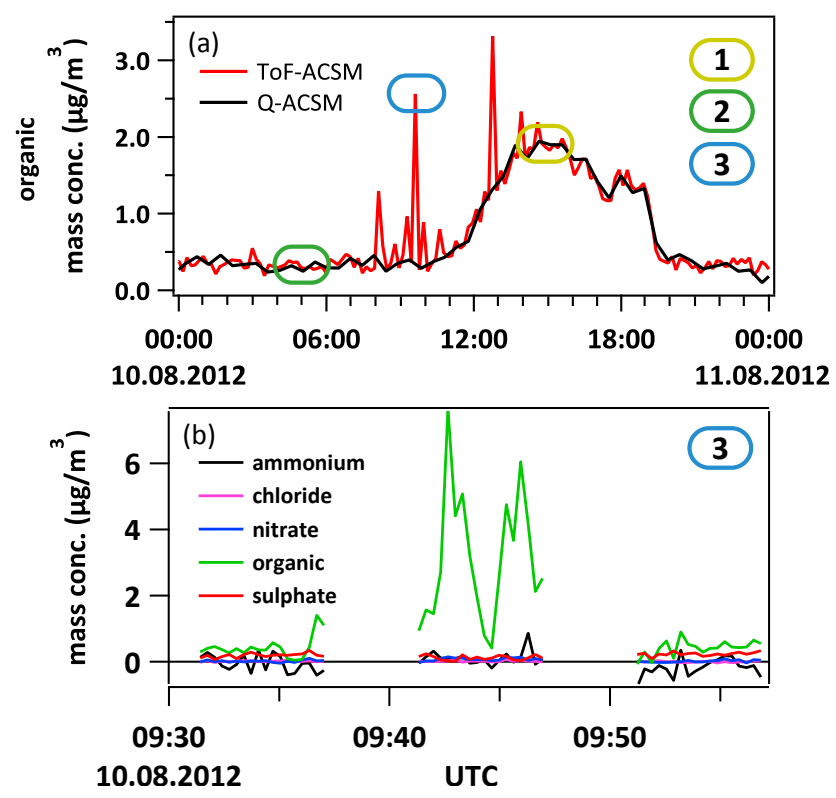

Fig. 5. (a) Organic mass concentrations measured on $10 \mathrm{Au}-$ gust 2012 with the ToF-ACSM (red line, time resolution: $10 \mathrm{~min}$ ) and the Q-ACSM (black line, time resolution: $30 \mathrm{~min}$ ). The average spectra recorded in the regions marked in yellow (14:00-16:00, case 1, higher concentrations), green (04:00-06:00, case 2, lower concentrations) and blue (10:00, case 3, short-term peak only seen by ToF-ACSM) are discussed in Fig. 6. (b) Time series during period 3 with the highest available time resolution of $20 \mathrm{~s}$. The gaps in the data indicate periods the instrument was acquiring the background concentrations.

(green, $\gamma_{\text {org }} \approx 0.35 \mu \mathrm{g} \mathrm{m}^{-3}$ ), and (3) during one of the peaks at 10:00 (blue).

The Q-ACSM (black line) operated with a time resolution of $30 \mathrm{~min}$ and the ToF-ACSM (red line) with a $10 \mathrm{~min}$ time resolution. The two time traces follow the same trend and show good agreement in terms of absolute concentration but the ToF-ACSM observes several short-term signal peaks. A closer look at one of the peaks (3, Fig. 5b) in the ToFACSM at $20 \mathrm{~s}$ time resolution demonstrates that this plume actually consists of two plumes, each of less than 3 min duration. There are two reasons why the Q-ACSM does not measure these plumes. First, the time resolution of the Q-ACSM measurements (30 $\mathrm{min}$ ) decreases ability of the instrument to resolve rapidly changing concentrations. More importantly, a fundamental difference exists between Q-ACSM and ToFACSM mass spectral acquisition, in that the ToF-ACSM acquires the entire mass spectrum simultaneously (i.e. with each extraction, see Fig. 1), while the Q-ACSM sequentially scans $m / Q$, with each scan cycle lasting several minutes. Thus, if the Q-ACSM is not scanning the relevant part of the mass spectrum during the plume, such a plume may go undetected or yield only a partial mass spectrum, biasing the measurement. Such a bias is evident in Fig. 5a in that averaging the ToF-ACSM data to the $30 \mathrm{~min}$ timescale of the Q-ACSM 
does not cause the instruments to agree, with the aerosol mass here significantly underestimated by the Q-ACSM. The veracity of the short duration peaks measured by the ToFACSM was verified by comparison with nephelometer data collected at $5 \mathrm{~min}$ time resolution (see Sect. 4.2.3 and Fig. 8).

Figure 6 shows Q-ACSM and ToF-ACSM mass spectra averaged over the periods identified in Fig. 5a, arranged as follows. The top panel shows the raw difference spectrum (calculated from the difference between the unfiltered and filtered raw spectrum) for the Q-ACSM during period 1, while the second panel shows the organic fraction of this spectrum integrated to integer $m / Q$ ("organic stick spectrum"). Panels 3 and 4 show the corresponding raw and organic stick spectra for the ToF-ACSM. The same plots are displayed for period 2 in panels 5 through 8 , while panel 9 gives the organic stick spectrum for period 3. To make the spectral patterns more visible, only the region between $m / Q=40 \mathrm{Th}$ and $100 \mathrm{Th}$ is shown and in some plots the $y$ axis is interrupted to show the high signals at $m / Q=43 \mathrm{Th}$ and $m / Q=44 \mathrm{Th}$. Coefficients of determination $\left(R^{2}\right)$ given in the following are calculated only for the part of the organic stick spectra between $m / Q=$ $45 \mathrm{Th}$ and $100 \mathrm{Th}$; otherwise the correlation is dominated by the high signals at, e.g. $m / Q=28 \mathrm{Th}$ or $m / Q=44 \mathrm{Th}$.

A comparison of both total raw difference spectrum and stick organic spectrum between Q-ACSM and ToF-ACSM for the case with the higher concentration (1) shows reasonable agreement $\left(R^{2}=0.62\right)$ except at the mass to charge ratios of naphthalene fragments $(m / Q=61-64 \mathrm{Th}, m / Q=74$ $78 \mathrm{Th}, m / Q=86-89 \mathrm{Th}$ and $m / Q=98-102 \mathrm{Th}$ ). This is expected because the Q-ACSM (for calibration reasons) has a source of naphthalene $\left(\mathrm{C}_{10} \mathrm{H}_{8}\right)$ incorporated inside the vacuum chamber ( $\mathrm{Ng}$ et al., 2011), constantly releasing molecules and therewith causing a larger background signal at the corresponding $m / Q$ ratios. Additional differences in the spectra originate from two short-lived plumes observed during the averaging period (cf. Fig. 5a), not being captured by the Q-ACSM due to the scanning of the quadrupole and lower temporal resolution. The correlation between QACSM and ToF-ACSM becomes much worse when the low concentration case 2 is compared. While the ToF-ACSM spectrum of case 2 remains similar to the ToF-ACSM spectrum of case $1\left(R^{2}=0.81\right)$, the Q-ACSM spectrum of case 2 now looks very different and even has some negative values at $m / Q$ 's influenced by naphthalene fragments. A $R^{2}$ of 0.19 between Q- and ToF-ACSM at case 2 confirms this observation. Looking at the raw difference spectra, one can easily recognise that while the ToF-ACSM spectrum still exhibits nicely separated, Gaussian-shaped signals, the Q-ACSM raw difference spectrum is noisy. The peaks are not as easily separable as in the raw difference spectrum of the Q-ACSM in case 1 . In summary these observations confirm that when sampling from the same inlet, the mass spectra of both instruments show a good agreement as long as the concentrations are well above the detection limit of the Q-ACSM. Approaching the detection limit $\left(\mathrm{DL}_{\mathrm{org}, 30 \mathrm{~min}}=0.136 \mu \mathrm{g} \mathrm{m}^{-3}\right)$, the quality of the Q-ACSM's mass spectrum deteriorates. The quality of the mass spectrum is crucial for the application of statistical source apportionment methods like positive matrix factorisation (PMF; Paatero, 1997; Paatero and Tapper, 1994) and the multilinear engine (ME-2; Paatero, 1999).

The organic stick spectrum of case 3 shown at the bottom of Fig. 6 looks significantly different to the two other rather similar ToF-ACSM spectra in cases 1 and 2 . The pronounced signals at the mass-to-charge ratios $41 \mathrm{Th}, 55 \mathrm{Th}, 57 \mathrm{Th}$ and $69 \mathrm{Th}$ point towards a significant fraction of hydrocarbonlike organics (HOA) in the aerosol. A comparison to an ambient mass spectrum of HOA from a campaign in Paris (Crippa et al., 2013) yields a good correlation with an $R^{2}$ of 0.78 for case 3, while the ToF-ACSM spectra in cases 1 and 2 do not correlate with the HOA spectrum $\left(R_{1}^{2}=0.42\right.$ and $R_{2}^{2}=0.22$ ). This result illustrates the utility of highly time resolved measurements even for monitoring applications, as here the local activity of machinery can be identified and distinguished from the rest of the data set.

The correlation in terms of absolute concentrations measured with the ToF- and Q-ACSM is illustrated in Fig. 7. On the top, the time series of organics, nitrate, sulphate, ammonium, and chloride measured with the ToF-ACSM during the first six months of the deployment are shown together with the corresponding inlet pressures and airbeam signal. These two parameters are used to account for changes in flow or detector gain as described in Sect. 3.1. It is noted that much of the variation in the airbeam signal observed in this time series arises from purposeful changes in settings for the optimisation of signal. The gaps in the time series have different reasons: planned interruptions to install hardware upgrades, software development, extended calibration and testing, or unplanned replacement of failed prototype power modules. The prototype stage has now concluded and the system has been running continuously for several months without interruption.

Figure 7c shows a two-week period (3 to 15 August) selected for further analysis of the ToF-ACSM/Q-ACSM intercomparison. The organic mass concentrations measured by the Q-ACSM (black line) and by the ToF-ACSM (red line, averaged to $30 \mathrm{~min}$ time resolution) are plotted on the same axis. Both instruments report approximately the same concentrations and exhibit good temporal correlation. The gap in this case was caused by a temporary interruption of the ioniser current due to a resolved hardware issue.

At the bottom left of Fig. 7, scatter plots of the mass concentrations of the four main species (chloride is not plotted because measured concentrations always were below detection limit at the Jungfraujoch) are shown. The data recorded with the ToF-ACSM are drawn on the $y$ axis and the data from the Q-ACSM on the $x$ axis. Slope and coefficient of determination retrieved with a least orthogonal distance fit to the scatter data for each species are given in the plots. There is a very good correlation for organics $\left(R^{2}=0.95\right.$, 

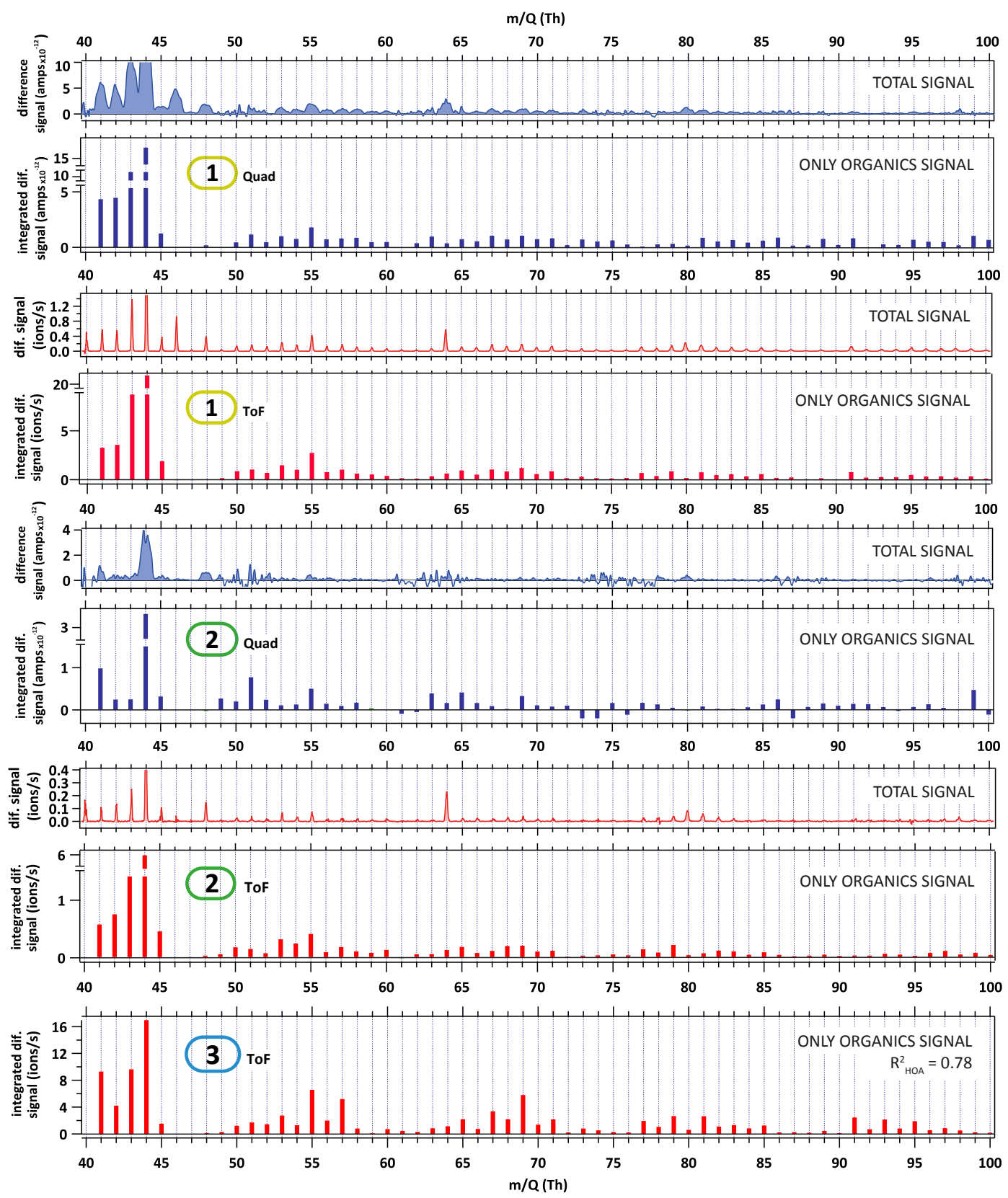

Fig. 6. Average spectra of the regions highlighted in Fig. 5. The spectra are grouped into four pairs of raw difference spectrum (calculated from the difference between the unfiltered and filtered raw spectrum) and the corresponding integrated UMR stick spectrum. The raw difference spectra show the total signal while the UMR stick spectra only show the organic fraction. Spectra recorded with the Q-ACSM are shown in blue and ToF-ACSM spectra in red. The first two pairs are from the afternoon period with the higher concentrations (1), the following two pairs are from the morning period with the lower concentrations, (2) and the last (9th) spectrum is from the peak, which was only seen with the ToF-ACSM (3). Coefficients of correlation were calculated for the spectral region between $m / Q=45 \mathrm{Th}$ and $100 \mathrm{Th}$. Between ToF-ACSM spectrum and Q-ACSM spectrum they are $R^{2}=0.62$ for case 1 and $R^{2}=0.19$ for case 2 . The $R^{2}$ given in the last plot shows the correlation to a reference HOA spectrum from (Crippa et al., 2013).

slope $=1.06)$, nitrate $\left(R^{2}=0.94\right.$, slope $\left.=0.95\right)$ and sulphate $\left(R^{2}=0.87\right.$, slope $\left.=1.16\right)$ between ToF- and Q-ACSM. The largest difference is found for ammonium, which still has a good correlation $\left(R^{2}=0.74\right.$, slope $\left.=1.30\right)$ but compared to the other species the scatter is larger and the ToF-ACSM measures higher values. This may be caused by additional noise in the scatter plot due to the low ammonium concentrations (maximum $0.5 \mu \mathrm{g} \mathrm{m}^{-3}$ ) typical of high altitude sites (Beig and Brasseur, 2000) and/or to the sensitivity of ammonium RIE to instrument tuning, where small errors in the 

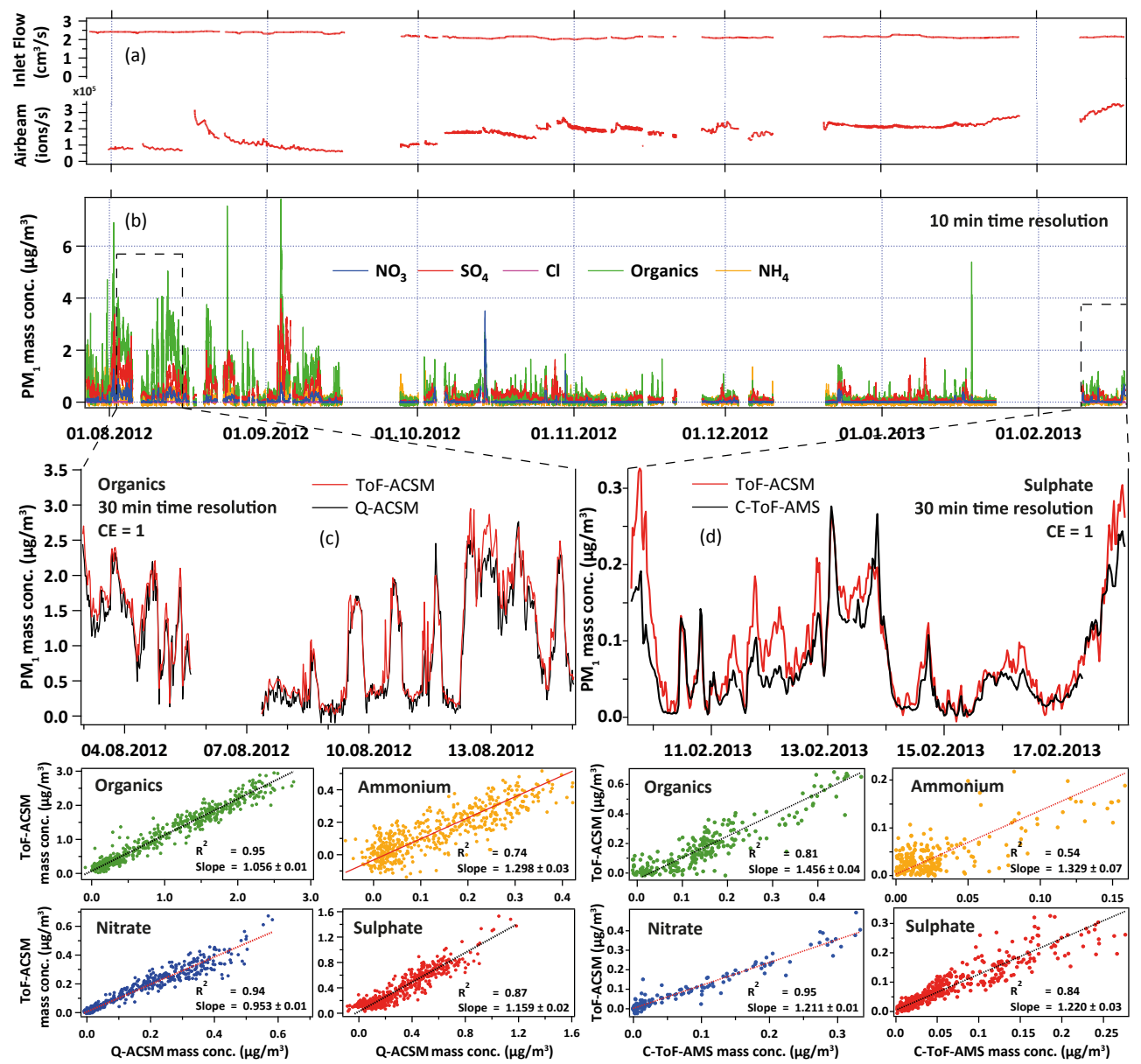

Fig. 7. Long-term time series and correlation of the ToF-ACSM to a Q-ACSM and a C-ToF-AMS. The two time series on the top show inlet pressure and airbeam variation during the $\sim 6$ months measurement period. These two parameters are used to correct for changes in the inlet flow or detector gain. Below the time series of the organics (green), $\mathrm{SO}_{4}$ (red), $\mathrm{NO}_{3}$ (blue), $\mathrm{NH}_{4}$ (orange) and chloride (pink) measured on the Jungfraujoch with a time resolution of 10 min are depicted. The periods 3-15 August 2012 and 9-18 February were enlarged to illustrate the correlation of the ToF-ACSM to Q-ACSM (left) and C-ToF-AMS (right). In each case the time trace of the organics measured with the two instruments (30 min time resolution) are shown together with the scatter plots of the other species. Coefficient of determination and slope in the comparison of the two ACSM are as follows: $R^{2}=0.95$, slope $=1.056$ (organics), $R^{2}=0.87$, slope $=1.159\left(\mathrm{SO}_{4}\right),\left(\mathrm{NO}_{3}\right) R^{2}=0.94$, slope $=0.953,\left(\mathrm{NH}_{4}\right) R^{2}=0.74$, slope $=1.298$. In the comparison to the C-ToF-AMS they are as follows: $R^{2}=0.81$, slope $=1.456$ (organics), $R^{2}=0.84$, slope $=1.220\left(\mathrm{SO}_{4}\right), R^{2}=0.95$, slope $=1.211\left(\mathrm{NO}_{3}\right), R^{2}=0.54$, slope $=1.329\left(\mathrm{NH}_{4}\right)$. Note the difference in the scale $($ dynamic range) between the comparison to the Q-ACSM in summer and the comparison to the C-ToF-AMS in winter.

calibration may propagate to biases in the ambient data. In the shown case the calibrations yielded $\mathrm{RIE}_{\mathrm{NH}_{4}}=3.4$ in the ToF-ACSM and $\mathrm{RIE}_{\mathrm{NH}_{4}}=5.4$ in the Q-ACSM.

\subsubsection{C-ToF-AMS}

ToF-ACSM and C-ToF-AMS were operated in parallel and connected to the same total inlet for slightly more than one week (9-18 February) during the INUIT-JFJ/CLACE2013 campaign at the Jungfraujoch site. However, the sampling line for the C-ToF-AMS was significantly longer than the one for the ToF-ACSM. Figure 7d shows the time series of sulphate (the dominant species at Jungfraujoch in winter).
A good correlation in both qualitative $\left(R^{2}=0.84\right)$ and quantitative (slope $=1.220$ ) terms was observed.

On the bottom right of Fig. 7, the correlation plots for the main species from this comparison are shown. Note that the (winter) concentrations for this intercomparison are much lower than the (summer) data investigated in the comparison with the Q-ACSM. Nevertheless, both instruments show a good correlation of the organics $\left(R^{2}=0.81\right.$, slope $=1.456)$, nitrate $\left(R^{2}=0.95\right.$, slope $\left.=1.211\right)$ and the aforementioned sulphate. The ammonium concentrations are below $0.05 \mu \mathrm{g} \mathrm{m}^{-3}$ most of the time, again leading to more noise in the scatter plot $\left(R^{2}=0.54\right.$, slope $\left.=1.329\right)$. Chloride is omitted due to concentrations below the detection limit during the whole period. 


\subsubsection{Scanning mobility particle sizer and nephelometer}

Nephelometer and SMPS examine different particle characteristics than those of the ToF-ACSM. The nephelometer measures the total and hemispheric scattering intensity of the aerosol at a given wavelength (Anderson and Ogren, 1998), while the SMPS measures the particle number size distribution via the size dependent mobility of charged particles in an electric field (Wang and Flagan, 1990). Nephelometer and aethalometer measurements often complement AMS or ACSM measurements for additional information on the refractory black carbon component of the aerosol and to provide indications on the presence of significant coarse particle concentrations. SMPS data are frequently used to estimate the collection efficiencies (CE) of ACSM or AMS. On these grounds it is important to investigate the correlation of the ToF-ACSM to these two instruments.

Typically, SMPS data are recorded bin-wise in $\mathrm{d} N / \mathrm{d} \log D_{\mathrm{p}}$ bin units. Here, $\mathrm{d} N$ is the particle concentration and $D_{\mathrm{p}}$ the midpoint mobility diameter of the particles in one logarithmic size bin. At the Jungfraujoch, the scanning range was $20-650 \mathrm{~nm}$. The specific set-up of the instrument is described by Jurányi et al. (2011). After a conversion of the number size distribution into total particle volume, the aerosol total mass concentration can be estimated by applying the correct density $\rho_{\mathrm{p}}$ of the particles. This $\rho_{\mathrm{p}}$ changes with time and can be estimated from the chemical composition measured by the ToF-ACSM (Salcedo et al., 2006; DeCarlo et al., 2004) under the condition that the refractory fraction of the aerosol (especially black carbon, BC) is either known or negligibly low, as is the case at Jungfraujoch. Based on the method specific uncertainties in the number concentration and diameter measurements, a propagated uncertainty of $20-30 \%$ is estimated for the calculated mass concentrations. Aside from the occasional helicopter flyby or temporary construction work, there are no local sources of $\mathrm{BC}$ and the refractory mineral dust particles blown over the Jungfraujoch during Saharan dust events are too large to be detected by either ToF-ACSM or SMPS. SMPS volume was converted to mass using an estimated density based on the densities of sulphuric acid $\left(\rho_{\mathrm{SO}_{4}^{2-}}=1.84 \mathrm{~g} \mathrm{~cm}^{-3}\right)$ and organics $\left(\rho_{\text {org,aged }}=1.27 \mathrm{~g} \mathrm{~cm}^{-3}\right.$; Cross et al., 2007) dependent on their fractional contributions to the total non-refractory $\mathrm{PM}_{1}$ mass, which together is above $80 \%$ over the whole year (cf. Fig. 7). The application of the density of sulphuric acid in these calculations (instead of the relatively similar $\rho_{\left(\mathrm{NH}_{4}\right)_{2} \mathrm{SO}_{4}}=1.77 \mathrm{~g} \mathrm{~cm}^{-3}$ or $\left.\rho_{\mathrm{NH}_{4} \mathrm{HSO}_{4}}=1.79 \mathrm{~g} \mathrm{~cm}^{-3}\right)$ provides the upper limit of the SMPS mass scale. This assumption is additionally justified by the low $\mathrm{NH}_{4}$ concentrations at the JFJ site, especially in winter, and suggests not completely neutralised aerosol during most of the year, as was reported by Cozic et al. (2008) and Lanz et al. (2010). The scatter plot depicted in Fig. 8a shows a good correlation $\left(R^{2}=0.80\right)$ between ToF-ACSM and SMPS during the whole $>6$ months
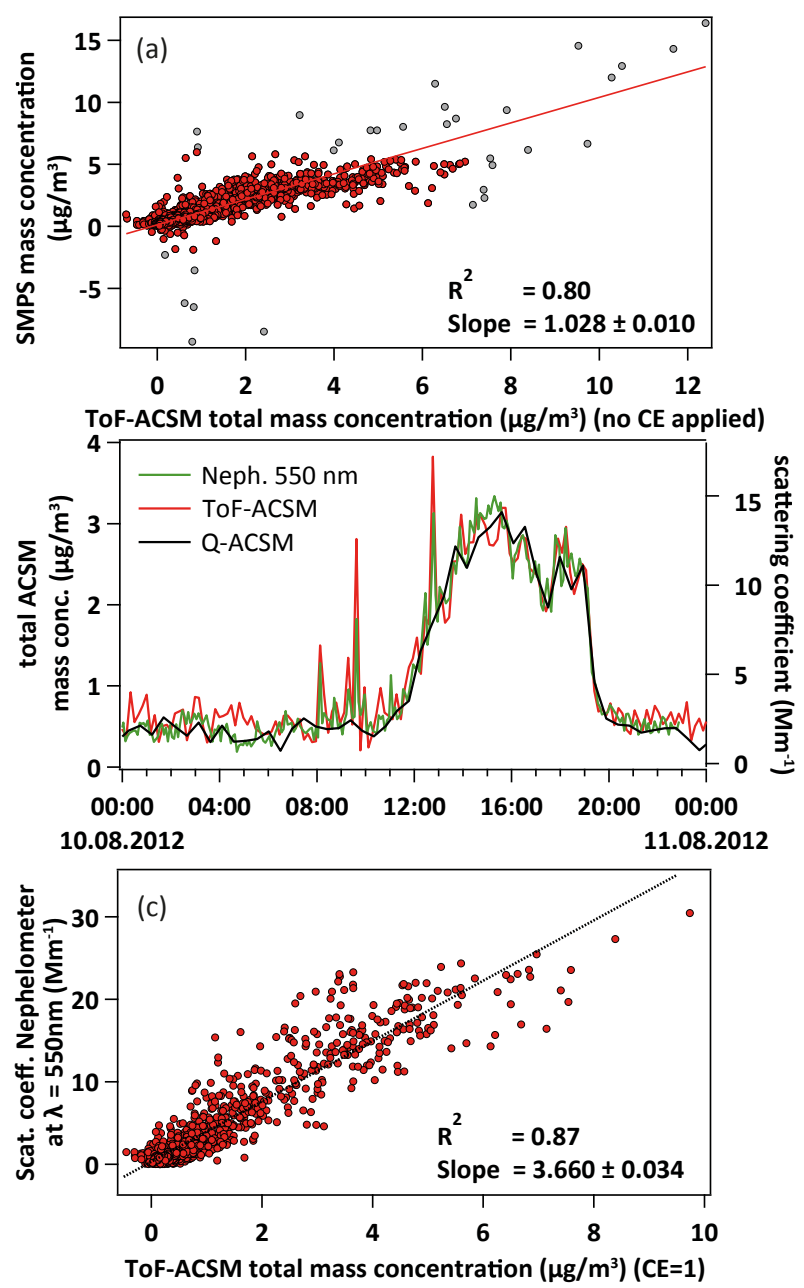

Fig. 8. (a) Scatter plot of the mass concentration calculated from an SMPS vs. the one from the ToF-ACSM. Greyed points were omitted in the linear orthogonal regression (red line). The two instruments correlate well $\left(R^{2}=0.80\right)$ and from the slope (1.028) a CE value close to unity (0.97) can be derived. (b) Total mass concentrations measured on 10 August 2012 with the ToF-ACSM (CE = 1, red line, time resolution: $10 \mathrm{~min})$, the $\mathrm{Q}-\mathrm{ACSM}(\mathrm{CE}=1$, black line, time resolution: $30 \mathrm{~min})$ and a nephelometer $(\lambda=550 \mathrm{~nm}$, green line, time resolution: $5 \mathrm{~min}$ ). The short-term plumes were detected by ToFACSM and nephelometer but not by the Q-ACSM. (c) Scatter plot of the scattering coefficient of the $\lambda=550 \mathrm{~nm}$ channel of a nephelometer vs. the mass concentration from the ToF-ACSM. Periods with supermicron or mineral dust particles were excluded. There is a good correlation between the scattering coefficient and the mass concentration of the ToF-ACSM $\left(R^{2}=0.87\right)$, and the slope $\left(3.66 \mathrm{~m}^{2} \mathrm{~g}^{-1}\right)$ lies within the range of previously reported MSEs (DeCarlo et al., 2008; Shinozuka et al., 2007).

measurement period. The greyed-out data points (one hour averages) were ignored in the displayed linear orthogonal fit. The ToF-ACSM vs. SMPS slope is 1.03, suggesting a CE value close to unity, which is consistent with previous AMS measurements at Jungfraujoch (Lanz et al., 2010; Jurányi et al., 2010). 
Figure $8 \mathrm{~b}$ shows the time series of the ToF-ACSM, the Q-ACSM and a nephelometer (total aerosol scattering coefficient of the green wavelength $\lambda=550 \mathrm{~nm}$ ) on the same day (10 August 2012) as shown in Fig. 5 for ToF- and Q-ACSM. The nephelometer data were corrected for truncation error and non-ideality of the lamp (Anderson and Odgen correction; Bond et al., 2009), it was operated at 5 min time resolution, making it capable of detecting events of short duration. The peaks which were only seen by the ToF-ACSM but not the Q-ACSM are also visible with a nephelometer but without chemically resolving the contributing species.

The nephelometer has no $\mathrm{PM}_{1}$ size cut, i.e. it also detects larger particles although the scattering signal at the Jungfraujoch is usually dominated by the submicron aerosol. This implies that during a Saharan dust event or during other pollution events that produce large particles (e.g. rock blasting or maintenance work in the Jungfraubahn train tunnels), the nephelometer measures higher signals than the ToFACSM. Although construction work is usually announced in advance, the days it is taking place can also be discerned with the help of an aethalometer (high absorption by BC from combustion). Saharan dust particles have a higher absorptivity and can be identified by looking at the slope of the Ångström exponent, a convolution of nephelometer and aethalometer intensities. Negative slopes indicate Saharan dust events (Collaud Coen et al., 2004). Figure 8c shows the scatter plot between the $\lambda=550 \mathrm{~nm}$ scattering signal of the nephelometer in $\mathrm{Mm}^{-1}$ and the total mass concentration measured with the ToF-ACSM in $\mu \mathrm{g} \mathrm{m}^{-3}$ after the exclusion of all construction work periods and Saharan dust events. The correlation between the two instruments is good $\left(R^{2}=0.87\right)$ and the slope of the linear regression $\left(3.66 \mathrm{~m}^{2} \mathrm{~g}^{-1}\right)$ is similar to previously reported AMS/nephelometer comparisons $\left(3.79 \mathrm{~m}^{2} \mathrm{~g}^{-1}\right.$; DeCarlo et al., 2008). This slope is analogous to the mass scattering efficiency (MSE) which was reported by Shinozuka et al. (2007) to lie around $3.6 \pm 1.3 \mathrm{~m}^{2} \mathrm{~g}^{-1}$ under dry conditions.

\subsection{High-resolution peak fitting with low-res mass analyser}

In addition to the information provided by applying the standard AMS fragmentation patterns to the integrated unitmass data, the ETOF mass analyser has sufficient resolution $(\mathrm{d} M=\mathrm{d}(m / Q))$ for the application of high-resolution peak fitting to determine the magnitude of individual ion signals present in the mass spectrum. It is noted that in this context the term high-resolution describes the possibility to achieve a separation of isobaric ion peaks in the mass spectrum and not the resolving power of the ETOF mass analyser itself.

The AMS electron-impact ionisation technique fragments molecules in a consistent manner and a constrained fitting technique, where the ions of interest are determined a priori and whose $m / Q$, peak shape and width are held constant in the fitting process - a technique that has been widely applied in the AMS literature (DeCarlo et al., 2006; Aiken et al., 2007; Zhang et al., 2011). In contrast to the HRToF-AMS, whose spectra are recorded with a mass resolving power of between 2000-4000, the ToF-ACSM records at only $\frac{M}{\Delta M} \approx 600$. This precludes a full high-resolution analysis as may be performed on AMS instruments equipped with high-resolution ToF spectrometers; in particular no information on nitrogen- or sulphur-containing organic compounds can be retrieved, owing to their close proximity to more dominant ions in the mass spectrum. Additionally, the ammonium ions are not sufficiently well separated from the air, water and organic background peaks to confidently calculate the ammonium time series from the $\mathrm{NH}^{+}, \mathrm{NH}_{2}^{+}$and $\mathrm{NH}_{3}^{+}$ions. However, the magnitudes of many other ions, in particular the $\mathrm{C}_{\mathrm{x}} \mathrm{H}_{\mathrm{y}}$ and $\mathrm{C}_{\mathrm{x}} \mathrm{H}_{\mathrm{y}} \mathrm{O}_{\mathrm{z}}$ families, may be successfully retrieved. This retrieval assumes that nitrogen and sulphur-containing organic fragments are insignificant compared to the designated families. This is however predominantly the case (Farmer et al., 2010). Inorganic nitrate and sulphate fragments can be retrieved well with this method.

To demonstrate this, we consider Fig. 9, which shows data taken at the Jungfraujoch during a period in which overnight construction work utilising diesel motors was taking place in the railway tunnel. These local emissions drifted upward over the period of a few hours and were eventually measured by the ToF-ACSM in the morning hours. Several spikes are apparent in the organic time series and the signal at $m / Q=57 \mathrm{Th}$, a well-used marker for the presence of saturated hydrocarbons (Alfarra et al., 2004), is elevated during these times. In contrast, adjacent time periods exhibit organics representative of the oxygenated regional background, with low to negligible $m / Q=57 \mathrm{Th}$ signal and elevated $m / Q=44 \mathrm{Th}$. The change in the organic profile is, however, also visible when considering two ions present at $m / Q=43 \mathrm{Th}$, namely the oxygenated organic $\mathrm{C}_{2} \mathrm{H}_{3} \mathrm{O}^{+}$ and the saturated $\mathrm{C}_{3} \mathrm{H}_{7}^{+}$. These have been previously used to demonstrate HR fitting on the AMS (DeCarlo et al., 2006; Müller et al., 2011). It is clear in Fig. 9 that the fitting procedure is able to successfully ascertain the elevation of the $\mathrm{C}_{3} \mathrm{H}_{7}^{+}$aerosol signal, i.e. the difference between the unfiltered and filtered measurements, during the period of local emissions. The contrast to the period without local influence is clear, in which the magnitudes of the $\mathrm{C}_{3} \mathrm{H}_{7}^{+}$fits for the unfiltered and filtered data are equal.

Cubison and Jimenez (2013) used simulations of constrained peak fitting of this nature to predict the degree of confidence to which adjacent and overlapping peak fits may be applied. From their conclusions, the uncertainty in the fitted amplitude of the two ions shown in Fig. 9 is less than $5 \%$ for the $\mathrm{C}_{2} \mathrm{H}_{3} \mathrm{O}^{+}$and less than $25 \%$ for the $\mathrm{C}_{3} \mathrm{H}_{7}^{+}$. For the fits shown in Fig. 9 for the period of local emissions, the sensitivity of the fitted amplitudes was probed by perturbing the mass calibration by $\pm 20 \mathrm{ppm}$, a realistic expected uncertainty for ToF-ACSM mass spectra. This yielded a change in the fitted 

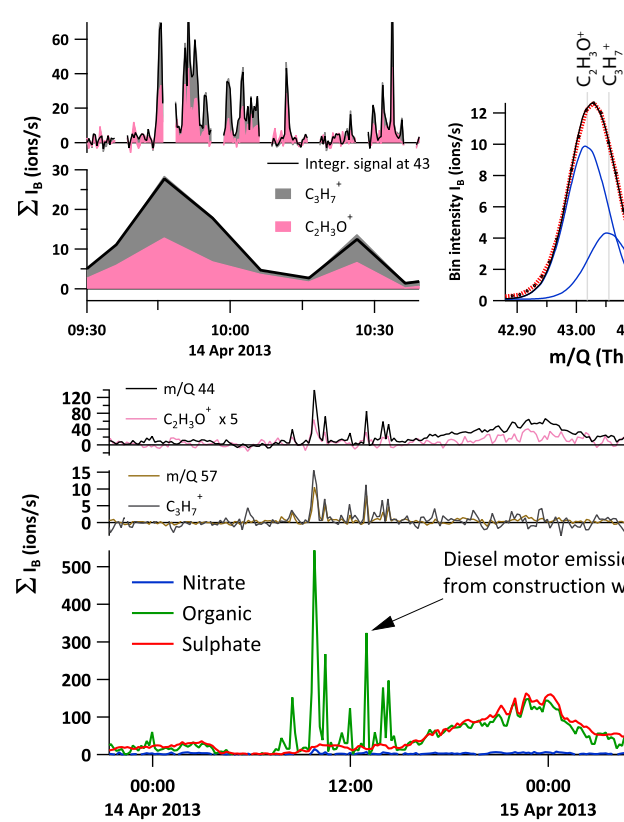
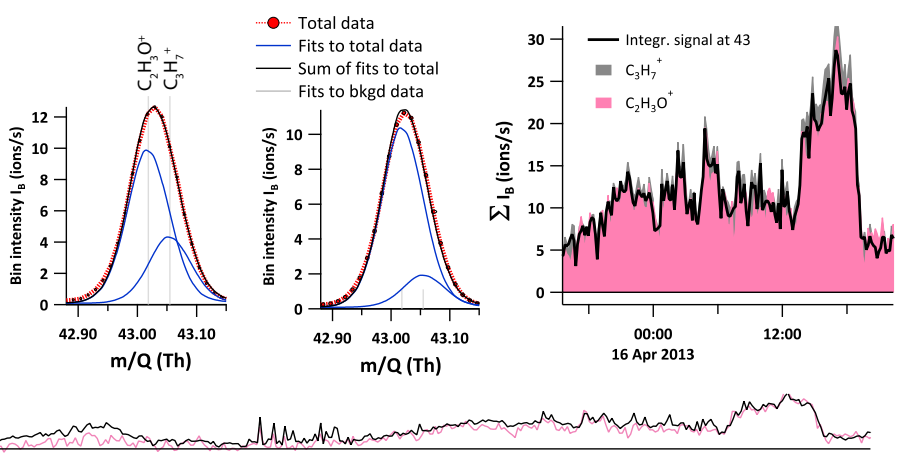

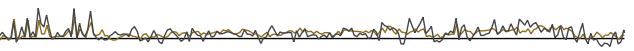

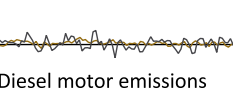

4

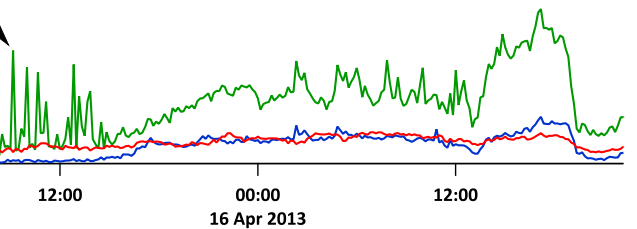

Fig. 9. Bottom: time series of organic and inorganic species measured by the ToF-ACSM at the Jungfraujoch. The integrated signal over the unit masses 44 and 57 is also shown. Top left: time series of high-resolution peak fits for two ions at $m / Q=43$ Th over a period with local emissions, together with the average mass spectrum for unfiltered data from this period. The peak fits for both filtered and unfiltered data are indicated in the plot. Top right: same for a period without influence of local emissions. All signals are shown in ions of the respective compounds per second.

$\mathrm{C}_{3} \mathrm{H}_{7}^{+}$amplitude of $\pm 8 \%$, in agreement with the predictions of Cubison and Jimenez (2013). By carefully considering other ions of interest, their $m / Q$ separations and expected amplitude ratios, significant further information may be confidently retrieved from ToF-ACSM mass spectra. An example of interest is the nitrate and sulphate ions. These can be confidently separated from the surrounding organic peaks, thus helping to determine the true magnitude of the inorganic signals during periods with high organic loading.

\section{Conclusions}

We present the ToF-ACSM, a new aerosol mass spectrometer optimised for long-term, stable, semi-autonomous environmental monitoring applications. Based on the Aerodyne aerosol mass spectrometer (AMS), it is built around the same sampling technology as the Q-ACSM but with a different vacuum system. It is equipped with a Tofwerk economy timeof-flight (ETOF) mass analyser. The ToF-ACSM continuously samples ambient particles, which are focused onto a resistively heated surface and flash vaporise, after which the resulting vapour is ionised by electron impact and detected by time-of-flight mass spectrometry. With a mass resolving power of $\frac{M}{\Delta M}=600$, the ToF provides a better resolution on the $m / Q$ axis and improves the detection limits compared to the Q-ACSM by species-dependent factors of 3 to 8 . Improvement by an additional factor of $\sim 8$ is expected to result from forthcoming simple upgrades, providing detection limits in the range of the C-ToF-AMS. The ToF-ACSM is specifically designed for unattended long-term monitoring applications. Instrument operation is therefore largely automated, with size, cost, and the need for on-site maintenance minimised.

To demonstrate the suitability of the ToF-ACSM for longterm unattended monitoring applications, a prototype instrument has been deployed for more than 10 months at the remote alpine site Jungfraujoch. Low detection limits are important there as ambient $\mathrm{PM}_{1}$ concentrations $\left(\mu \mathrm{g} \mathrm{m}^{-3}\right)$ usually are in the single digits and below. During this deployment the ToF-ACSM was compared to several co-located instruments. A good agreement with correlation coefficients $\left(R^{2}\right)$ above 0.8 to Q-ACSM and C-ToF-AMS was found for the organics, sulphate and nitrate fractions. The correlation of the ammonium fraction was slightly worse due to very low ammonium signals during the intercomparison periods, i.e. bad signal-to-noise ratio $\left(R^{2}(\mathrm{Q}-\mathrm{ACSM})=0.74, R^{2}(\mathrm{C}\right.$-ToFAMS $)=0.54$ ). Quantitative agreement is shown by slopes close to unity for all species (C-ToF-AMS: 1.21-1.46; QACSM: 0.95-1.30). Comparison with a scanning mobility particle sizer (SMPS) and nephelometer yield similarly good agreements. We demonstrated the possibility to apply mass defect resolved peak fitting (e.g. separation of $\mathrm{C}_{3} \mathrm{H}_{7}^{+}$and $\mathrm{C}_{2} \mathrm{H}_{3} \mathrm{O}^{+}$, both occurring at $m / Q=43 \mathrm{Th}$ ) to determine the magnitude of individual ion signals present in the mass spectrum. 
Acknowledgements. This work was supported by the Swiss Commission for Technology and Innovation, the European FP-7 project ACTRIS, the Federal Office for the Environment, the German Science Foundation (DFG, FOR 1525 "INUIT") as well as the Swiss National Science Foundation. J. Slowik is supported by the SNF through the Ambizione program. Research for this article benefited from the association of M. J. Cubison, J. R. Kimmel, Urs Rohner, and M. Gonin with Tofwerk AG. Aerodyne Research would like to acknowledge United States Department of Energy SBIR Grant DE-SC0001673 which in part helped support this work.

We thank the International Foundation High Altitude Research Stations Jungfraujoch and Gornergrat (HFSJG) for the opportunity to perform experiments on the Jungfraujoch as well as the custodians Joan \& Martin Fischer and Maria \& Urs Otz who always make sure things are going smoothly. Our thanks also go to Paul Zieger and Emanuel Hammer for their support with nephelometer, aethalometer and SMPS.

Edited by: P. Herckes

\section{References}

Aiken, A. C., DeCarlo, P. F., and Jimenez, J. L.: Elemental analysis of organic species with electron ionization high-resolution mass spectrometry, Anal. Chem., 79, 8350-8358, 2007.

Alfarra, M. R., Coe, H., Allan, J. D., Bower, K. N., Boudries, H., Canagaratna, M. R., Jimenez, J. L., Jayne, J. T., Garforth, A. A., Li, S.-M., and Worsnop, D. R.: Characterization of urban and rural organic particulate in the Lower Fraser Valley using two Aerodyne Aerosol Mass Spectrometers, Atmos. Environ., 38, 5745-5758, 2004.

Allan, J. D., Delia, A. E., Coe, H., Bower, K. N., Alfarra, M., Jimenez, J. L., Middlebrook, A. M., Drewnick, F., Onasch, T. B., Canagaratna, M. R., Jayne, J. T., and Worsnop, D. R.: A generalised method for the extraction of chemically resolved mass spectra from Aerodyne aerosol mass spectrometer data, J. Aerosol Sci., 35, 909-922, 2004.

Anderson, T. L. and Ogren, J. A.: Determining aerosol radiative properties using the TSI 3563 integrating nephelometer, Aerosol Sci. Tech., 29, 57-69, 1998.

BAFU: NABEL - Luftbelastung 2011: Messresultate des Nationalen Beobachtungsnetzes für Luftfremdstoffe (NABEL), Tech. rep., Umwelt-Zustand Nr. 1221, Bundesamt für Umwelt, Bern, Switzerland, 2012.

Beig, G. and Brasseur, G. P.: Model of tropospheric ion composition: a first attempt, J. Geophys. Res.-Atmos., 105, 2267122684, 2000.

Bond, T. C., Covert, D. S., and Müller, T.: Truncation and angularscattering corrections for absorbing aerosol in the TSI 3563 nephelometer, Aerosol Sci. Tech., 43, 866-871, 2009.

Budisulistiorini, S. H., Canagaratna, M. R., Croteau, P. L., Marth, W. J., Baumann, K., Edgerton, E. S., Shaw, S. L., Knipping, E. M., Worsnop, D. R., Jayne, J. T., Gold, A., and Surratt, J. D.: Real-time continuous characterization of secondary organic aerosol derived from isoprene epoxydiols in downtown Atlanta, Georgia, using the Aerodyne aerosol chemical speciation monitor, Environ. Sci. Technol., 47, 5686-5694, 2013.

Canagaratna, M., Jayne, J., Jimenez, J., Allan, J., Alfarra, M., Zhang, Q., Onasch, T., Drewnick, F., Coe, H., Middlebrook, A.,
Delia, A., Williams, L., Trimborn, A., Northway, M., DeCarlo, P., Kolb, C., Davidovits, P., and Worsnop, D.: Chemical and microphysical characterization of ambient aerosols with the aerodyne aerosol mass spectrometer, Mass Spectrom. Rev., 26, 185-222, 2007.

Canonaco, F., Crippa, M., Slowik, J. G., Baltensperger, U., and Prévôt, A. S. H.: SoFi, an Igor based interface for the efficient use of the generalized multilinear engine (ME-2) for source apportionment: application to aerosol mass spectrometer data, Atmos. Meas. Tech. Discuss., 6, 6409-6443, doi:10.5194/amtd-66409-2013, 2013.

Carslaw, K. S., Boucher, O., Spracklen, D. V., Mann, G. W., Rae, J. G. L., Woodward, S., and Kulmala, M.: A review of natural aerosol interactions and feedbacks within the Earth system, Atmos. Chem. Phys., 10, 1701-1737, doi:10.5194/acp-10-17012010, 2010.

Cohen, A. J., Ross Anderson, H., Ostro, B., Pandey, K. D., Krzyzanowski, M., Kunzli, N., Gutschmidt, K., Pope, A., Romieu, I., Samet, J. M., and Smith, K.: The global burden of disease due to outdoor air pollution, J. Toxicol. Env. Heal. A, 68, 1301-1307, 2005.

Collaud Coen, M., Weingartner, E., Schaub, D., Hueglin, C., Corrigan, C., Henning, S., Schwikowski, M., and Baltensperger, U.: Saharan dust events at the Jungfraujoch: detection by wavelength dependence of the single scattering albedo and first climatology analysis, Atmos. Chem. Phys., 4, 2465-2480, doi:10.5194/acp4-2465-2004, 2004.

Cozic, J., Verheggen, B., Weingartner, E., Crosier, J., Bower, K. N., Flynn, M., Coe, H., Henning, S., Steinbacher, M., Henne, S., Collaud Coen, M., Petzold, A., and Baltensperger, U.: Chemical composition of free tropospheric aerosol for $\mathrm{PM}_{1}$ and coarse mode at the high alpine site Jungfraujoch, Atmos. Chem. Phys., 8, 407-423, doi:10.5194/acp-8-407-2008, 2008.

Crippa, M., DeCarlo, P. F., Slowik, J. G., Mohr, C., Heringa, M. F., Chirico, R., Poulain, L., Freutel, F., Sciare, J., Cozic, J., Di Marco, C. F., Elsasser, M., Nicolas, J. B., Marchand, N., Abidi, E., Wiedensohler, A., Drewnick, F., Schneider, J., Borrmann, S., Nemitz, E., Zimmermann, R., Jaffrezo, J.-L., Prévôt, A. S. H., and Baltensperger, U.: Wintertime aerosol chemical composition and source apportionment of the organic fraction in the metropolitan area of Paris, Atmos. Chem. Phys., 13, 961-981, doi:10.5194/acp-13-961-2013, 2013.

Cross, E. S., Slowik, J. G., Davidovits, P., Allan, J. D., Worsnop, D. R., Jayne, J. T., Lewis, D. K., Canagaratna, M., and Onasch, T. B.: Laboratory and ambient particle density determinations using light scattering in conjunction with aerosol mass spectrometry, Aerosol Sci. Tech., 41, 343-359, 2007.

Cubison, M. J. and Jimenez, J. L.: Atmos. Meas. Tech. Discuss., in preparation, 2013.

DeCarlo, P. F., Slowik, J. G., Worsnop, D. R., Davidovits, P., and Jimenez, J. L.: Particle morphology and density characterization by combined mobility and aerodynamic diameter measurements, Pt. 1: theory, Aerosol Sci. Tech., 38, 1185-1205, 2004.

DeCarlo, P. F., Kimmel, J. R., Trimborn, A., Northway, M. J., Jayne, J. T., Aiken, A. C., Gonin, M., Fuhrer, K., Horvath, T., Docherty, K. S., Worsnop, D. R., and Jimenez, J. L.: Fielddeployable, high-resolution, time-of-flight aerosol mass spectrometer, Anal. Chem., 78, 8281-8289, 2006. 
DeCarlo, P. F., Dunlea, E. J., Kimmel, J. R., Aiken, A. C., Sueper, D., Crounse, J., Wennberg, P. O., Emmons, L., Shinozuka, Y., Clarke, A., Zhou, J., Tomlinson, J., Collins, D. R., Knapp, D., Weinheimer, A. J., Montzka, D. D., Campos, T., and Jimenez, J. L.: Fast airborne aerosol size and chemistry measurements above Mexico City and Central Mexico during the MILAGRO campaign, Atmos. Chem. Phys., 8, 4027-4048, doi:10.5194/acp-84027-2008, 2008.

Drewnick, F., Hings, S. S., DeCarlo, P., Jayne, J. T., Gonin, M., Fuhrer, K., Weimer, S., Jimenez, J. L., Demerjian, K. L., Borrmann, S., and Worsnop, D. R.: A new time-of-flight aerosol mass spectrometer (TOF-AMS) - instrument description and first field deployment, Aerosol Sci. Tech., 39, 637-658, 2005.

Drewnick, F., Hings, S. S., Alfarra, M. R., Prevot, A. S. H., and Borrmann, S.: Aerosol quantification with the Aerodyne Aerosol Mass Spectrometer: detection limits and ionizer background effects, Atmos. Meas. Tech., 2, 33-46, doi:10.5194/amt-2-332009, 2009.

Farmer, D. K., Matsunaga, A., Docherty, K. S., Surratt, J. D., Seinfeld, J. H., Ziemann, P. J., and Jimenez, J. L.: Response of an aerosol mass spectrometer to organonitrates and organosulfates and implications for atmospheric chemistry, P. Natl. Acad. Sci. USA, 107, 6670-6675, 2010.

Forster, P., Ramaswamy, V., Artaxo, P., Berntsen, T., Betts, R., Fahey, D., Haywood, J., Lean, J., Lowe, D., Myhre, G., Nganga, J., Prinn, R., Raga, G., Schulz, M., and Van Dorland, R.: Changes in atmospheric constituents and in radiative forcing, in: Climate change 2007: the Physical Science Basis., in: Contribution of Working Group I to the Fourth Assessment Report of the Intergovernmental Panel on Climate Change, edited by: Solomon, S., Qin, D., Manning, M., Chen, Z., Marquis, M., Averyt, K., Tignor, M., and Miller, H. L., Cambridge University Press, Cambridge, UK and NY, NY, USA, 129-234, 2007.

Gu, L., Baldocchi, D. D., Wofsy, S. C., Munger, J. W., Michalsky, J. J., Urbanski, S. P., and Boden, T. A.: Response of a deciduous forest to the Mount Pinatubo eruption: enhanced photosynthesis, Science, 299, 2035-2038, 2003.

Henne, S., Furger, M., Nyeki, S., Steinbacher, M., Neininger, B., de Wekker, S. F. J., Dommen, J., Spichtinger, N., Stohl, A., and Prévôt, A. S. H.: Quantification of topographic venting of boundary layer air to the free troposphere, Atmos. Chem. Phys., 4, 497509, doi:10.5194/acp-4-497-2004, 2004.

Jayne, J., Leard, D., Zhang, X., Davidovits, P., Smith, K., Kolb, C., and Worsnop, D.: Development of an aerosol mass spectrometer for size and composition analysis of submicron particles, Aerosol Sci. Tech., 33, 49-70, 2000.

Jimenez, J. L., Jayne, J. T., Shi, Q., Kolb, C. E., Worsnop, D. R., Yourshaw, I., Seinfeld, J. H., Flagan, R. C., Zhang, X., Smith, K. A., Morris, J. W., and Davidovits, P.: Ambient aerosol sampling using the Aerodyne Aerosol Mass Spectrometer, J. Geophys. Res.-Atmos., 108, 8425, doi:10.1029/2001JD001213, 2003.

Jimenez, J. L., Canagaratna, M. R., Donahue, N. M., Prévôt, A. S. H., Zhang, Q., Kroll, J. H., DeCarlo, P. F., Allan, J. D., Coe, H., Ng, N. L., Aiken, A. C., Docherty, K. S., Ulbrich, I. M., Grieshop, A. P., Robinson, A. L., Duplissy, J., Smith, J. D., Wilson, K. R., Lanz, V. A., Hueglin, C., Sun, Y. L., Tian, J., Laaksonen, A., Raatikainen, T., Rautiainen, J., Vaattovaara, P., Ehn, M., Kulmala, M., Tomlinson, J. M., Collins, D. R.,
Cubison, M. J. E., Dunlea, J., Huffman, J. A., Onasch, T. B., Alfarra, M. R., Williams, P. I., Bower, K., Kondo, Y., Schneider, J., Drewnick, F., Borrmann, S., Weimer, S., Demerjian, K., Salcedo, D., Cottrell, L., Griffin, R., Takami, A., Miyoshi, T., Hatakeyama, S., Shimono, A., Sun, J. Y., Zhang, Y. M., Dzepina, K., Kimmel, J. R., Sueper, D., Jayne, J. T., Herndon, S. C., Trimborn, A. M., Williams, L. R., Wood, E. C., Middlebrook, A. M., Kolb, C. E., Baltensperger, U., and Worsnop, D. R.: Evolution of organic aerosols in the atmosphere, Science, 326, 1525-1529, 2009.

Jurányi, Z., Gysel, M., Weingartner, E., DeCarlo, P. F., Kammermann, L., and Baltensperger, U.: Measured and modelled cloud condensation nuclei number concentration at the high alpine site Jungfraujoch, Atmos. Chem. Phys., 10, 7891-7906, doi:10.5194/acp-10-7891-2010, 2010.

Jurányi, Z., Gysel, M., Weingartner, E., Bukowiecki, N., Kammermann, L., and Baltensperger, U.: A 17 month climatology of the cloud condensation nuclei number concentration at the high alpine site Jungfraujoch, J. Geophys. Res.-Atmos., 116, D10204, doi:10.1029/2010JD015199, 2011.

Kimmel, J. R., Farmer, D. K., Cubison, M. J., Sueper, D., Tanner, C., Nemitz, E., Worsnop, D. R., Gonin, M., and Jimenez, J. L.: Real-time aerosol mass spectrometry with millisecond resolution, Int. J. Mass Spectrom., 303, 15-26, 2011.

Laden, F., Neas, L. M., Dockery, D. W., and Schwartz, J.: Association of fine particulate matter from different sources with daily mortality in six US cities, Environ. Health Persp., 108, 941-947, 2000.

Lanz, V. A., Prévôt, A. S. H., Alfarra, M. R., Weimer, S., Mohr, C., DeCarlo, P. F., Gianini, M. F. D., Hueglin, C., Schneider, J., Favez, O., D’Anna, B., George, C., and Baltensperger, U.: Characterization of aerosol chemical composition with aerosol mass spectrometry in Central Europe: an overview, Atmos. Chem. Phys., 10, 10453-10471, doi:10.5194/acp-10-10453-2010, 2010.

Liu, P., Ziemann, P. J., Kittelson, D. B., and McMurry, P. H.: Generating particle beams of controlled dimensions and divergence: II. experimental evaluation of particle motion in aerodynamic lenses and nozzle expansions, Aerosol Sci. Tech., 22, 314-324, 1995a.

Liu, P., Ziemann, P. J., Kittelson, D. B., and McMurry, P. H.: Generating particle beams of controlled dimensions and divergence: I. Theory of particle motion in aerodynamic lenses and nozzle expansions, Aerosol Sci. Tech., 22, 293-313, 1995 b.

Liu, P. S. K., Deng, R., Smith, K. A., Williams, L. R., Jayne, J. T., Canagaratna, M. R., Moore, K., Onasch, T. B., Worsnop, D. R., and Deshler, T.: Transmission efficiency of an aerodynamic focusing lens system: comparison of model calculations and laboratory measurements for the Aerodyne Aerosol Mass Spectrometer, Aerosol Sci. Tech., 41, 721-733, 2007.

Lohmann, U. and Feichter, J.: Global indirect aerosol effects: a review, Atmos. Chem. Phys., 5, 715-737, doi:10.5194/acp-5-7152005, 2005.

Lugauer, M., Baltensperger, U., Furger, M., Gäggeler, H., Jost, D., Schwikowski, M., and Wanner, H.: Aerosol transport to the high Alpine sites Jungfraujoch (3454 masl) and Colle Gnifetti (4452 masl), Tellus B, 50, 76-92, doi:10.3402/tellusb.v50i1.16026, 1998.

Mahowald, N.: Aerosol indirect effect on biogeochemical cycles and climate, Science, 334, 794-796, 2011. 
Matthew, B. M., Middlebrook, A. M., and Onasch, T. B.: Collection efficiencies in an Aerodyne aerosol mass spectrometer as a function of particle phase for laboratory generated aerosols, Aerosol Sci. Tech., 42, 884-898, 2008.

Mercado, L. M., Bellouin, N., Sitch, S., Boucher, O., Huntingford, C., Wild, M., and Cox, P. M.: Impact of changes in diffuse radiation on the global land carbon sink, Nature, 458, 10141017, 2009.

Middlebrook, A. M., Bahreini, R., Jimenez, J. L., and Canagaratna, M. R.: Evaluation of composition-dependent collection efficiencies for the Aerodyne Aerosol Mass Spectrometer using field data, Aerosol Sci. Tech., 46, 258-271, 2012.

Müller, M., George, C., and D'Anna, B.: Enhanced spectral analysis of C-TOF aerosol mass spectrometer data: iterative residual analysis and cumulative peak fitting, Int. J. Mass Spectrom., 306, $1-8,2011$.

Ng, N. L., Herndon, S. C., Trimborn, A., Canagaratna, M. R., Croteau, P. L., Onasch, T. B., Sueper, D., Worsnop, D. R., Zhang, Q., Sun, Y. L., and Jayne, J. T.: An Aerosol Chemical Speciation Monitor (ACSM) for routine monitoring of the composition and mass concentrations of ambient aerosol, Aerosol Sci. Tech., 45, 780-794, 2011.

Onasch, T. B., Trimborn, A., Fortner, E. C., Cross, E., Hunter, J. F., Massoli, P., Jayne, J. T., Williams, L. R., Kok, G. L., Kroll, J. H., Davidovits, P., and Worsnop, D. R.: SP-AMS, in: 12th AMS Users Meeting, 1 October 2011, Orlando, FL, USA, 2011.

Paatero, P.: Least squares formulation of robust non-negative factor analysis, Chemometr. Intell. Lab., 37, 223-242, doi:10.1016/S0169-7439(97)00031-2, 1997.

Paatero, P.: The multilinear engine - a table-driven, least squares program for solving multilinear problems, including the n-way parallel factor analysis model, J. Comput. Graph. Stat., 8, 854888,1999

Paatero, P. and Tapper, U.: Positive matrix factorization: a nonnegative factor model with optimal utilization of error estimates of data values, Environmetrics, 5, 111-126, 1994.

Pope, C. A. and Dockery, D. W.: Health effects of fine particulate air pollution: lines that connect, J. Air Waste Manage., 56, 709-742, 2006.

Salcedo, D., Onasch, T. B., Dzepina, K., Canagaratna, M. R., Zhang, Q., Huffman, J. A., DeCarlo, P. F., Jayne, J. T., Mortimer, P., Worsnop, D. R., Kolb, C. E., Johnson, K. S., Zuberi, B., Marr, L. C., Volkamer, R., Molina, L. T., Molina, M. J., Cardenas, B., Bernabé, R. M., Márquez, C., Gaffney, J. S., Marley, N. A., Laskin, A., Shutthanandan, V., Xie, Y., Brune, W., Lesher, R., Shirley, T., and Jimenez, J. L.: Characterization of ambient aerosols in Mexico City during the MCMA-2003 campaign with Aerosol Mass Spectrometry: results from the CENICA Supersite, Atmos. Chem. Phys., 6, 925-946, doi:10.5194/acp-6-925-2006, 2006.
Seaton, A., Godden, D., MacNee, W., and Donaldson, K.: Particulate air pollution and acute health effects, Lancet, 345, 176-178, 1995.

Seto, T., Kim, S., Otani, Y., Takami, A., Kaneyasu, N., Fujimoto, T., Okuyama, K., Takamura, T., and Hatakeyama, S.: New particle formation and growth associated with East-Asian long range transportation observed at Fukue Island, Japan in March 2012, Atmos. Environ., 74, 29-36, 2013.

Shinozuka, Y., Clarke, A. D., Howell, S. G., Kapustin, V. N., McNaughton, C. S., Zhou, J., and Anderson, B. E.: Aircraft profiles of aerosol microphysics and optical properties over North America: aerosol optical depth and its association with $\mathrm{PM}_{2.5}$ and water uptake, J. Geophys. Res.-Atmos., 112, D12S20, doi:10.1029/2006JD007918, 2007.

Sun, Y., Wang, Z., Dong, H., Yang, T., Li, J., Pan, X., Chen, P., and Jayne, J. T.: Characterization of summer organic and inorganic aerosols in Beijing, China with an Aerosol Chemical Speciation Monitor, Atmos. Environ., 51, 250-259, 2012.

Sun, Y. L., Wang, Z. F., Fu, P. Q., Yang, T., Jiang, Q., Dong, H. B., Li, J., and Jia, J. J.: Aerosol composition, sources and processes during wintertime in Beijing, China, Atmos. Chem. Phys., 13, 4577-4592, doi:10.5194/acp-13-4577-2013, 2013.

Takahama, S., Johnson, A., Morales, J. G., Russell, L., Duran, R., Rodriguez, G., Zheng, J., Zhang, R., Toom-Sauntry, D., and Leaitch, W.: Submicron organic aerosol in Tijuana, Mexico, from local and Southern California sources during the CalMex campaign, Atmos. Environ., 70, 500-512, 2013.

Wang, S. C. and Flagan, R. C.: Scanning electrical mobility spectrometer, Aerosol Sci. Tech., 13, 230-240, 1990.

Williams, L. R., Gonzalez, L. A., Peck, J., Trimborn, D., McInnis, J., Farrar, M. R., Moore, K. D., Jayne, J. T., Robinson, W. A., Lewis, D. K., Onasch, T. B., Canagaratna, M. R., Trimborn, A., Timko, M. T., Magoon, G., Deng, R., Tang, D., de la Rosa Blanco, E., Prévôt, A. S. H., Smith, K. A., and Worsnop, D. R.: Characterization of an aerodynamic lens for transmitting particles $>1$ micrometer in diameter into the Aerodyne aerosol mass spectrometer, Atmos. Meas. Tech. Discuss., 6, 5033-5063, doi:10.5194/amtd-6-5033-2013, 2013.

Zhang, Q., Jimenez, J. L., Canagaratna, M. R., Ulbrich, I. M., Ng, N. L., Worsnop, D. R., and Sun, Y.: Understanding atmospheric organic aerosols via factor analysis of aerosol mass spectrometry: a review, Anal. Bioanal. Chem., 401, 3045-3067, 2011.

Zhang, X., Smith, K. A., Worsnop, D. R., Jimenez, J. L., Jayne, J. T., Kolb, C. E., Morris, J., and Davidovits, P.: Numerical characterization of particle beam collimation: part II integrated aerodynamic-lens-nozzle system, Aerosol Sci. Tech., 38, 619638, 2004. 